\title{
Digital finance innovation in green manufacturing: a bibliometric approach
}

\author{
Lei Chang ${ }^{1} \cdot$ Qi Zhang ${ }^{2} \cdot$ Hongda Liu ${ }^{3}$
}

Received: 6 September 2021 / Accepted: 5 December 2021

() The Author(s), under exclusive licence to Springer-Verlag GmbH Germany, part of Springer Nature 2021

\begin{abstract}
In the era of Industry 4.0, the innovative applications of the industrial internet of things continue to deepen, and the trend of digital transformation of the green manufacturing industry continues to expand. In this context, the study of digital finance innovation in green manufacturing enterprises is conducive to transforming and upgrading enterprises and national economic development. In order to review the theoretical foundations and the current state of research under this topic, this paper provides an overview of digital finance innovation in green manufacturing companies based on 296 papers published between 1900 and 2021 through bibliometric and scientific visualization methods. This paper uses HistCite to identify the most influential authors, institutions, and countries and uncover the lineage of research on digital finance innovation in green manufacturing companies. At the same time, VOSviewer is used to identify research hotspots and research clusters under the topic. Finally, on this basis, this paper classifies the types of digital innovation from the perspective of value creation. It proposes a theoretical framework for the realization path of digital finance innovation in green manufacturing enterprises based on intelligent servitization and orchestration capabilities. The findings of this paper enrich the existing innovation theory and facilitate scholars to conduct future research more effectively.
\end{abstract}

Keywords Digital finance innovation $\cdot$ Green manufacturing $\cdot$ Bibliometric $\cdot$ Intelligent servitization $\cdot$ Orchestration capability

\section{Introduction}

With the cluster of innovative breakthroughs in new-generation digital technologies such as big data, cloud computing, artificial intelligence, and the industrial internet,

Responsible Editor: Ilhan Ozturk

Hongda Liu

liuhoda@163.com

Lei Chang

chang06@mail.ustc.edu.cn

Qi Zhang

qi_zhang_zq@163.com

1 Science \& Technology University, Beijing, China

2 Rensselaer Polytechnic Institute, Lally Business College, Troy, NY, USA

3 School of Economics \& Management, Tongji University, Shanghai, China digital innovation has produced profound changes to the development model of the green manufacturing industry. The global green manufacturing landscape is undergoing profound changes. On the one hand, developed countries are committed to industrial redevelopment strategies to compete for and maintain their positions at the top end of the global industrial chain. On the other hand, the green manufacturing industries of resource-intensive emerging countries are moving towards the middle and high ends, such as the dual international and domestic cycle strategy that China has begun to pursue. In this context, it is therefore essential and urgent to study digital innovation in green manufacturing.

On the other hand, COVID-19 has had a great negative impact on society and the economy. How to achieve a new round of revolution in development through the integration of new manufacturing and green development has become a realistic problem for governments of all countries. As the backbone of the economies of various countries, the importance of green manufacturing is self-evident, but under the damage of the epidemic, green manufacturing urgently 
needs the influx of new financial capital. With the strong support of green finance, the production efficiency of green manufacturing has been rapidly improved. In this process, governments such as China took the lead in proposing digital finance. Through the introduction of digital finance and the development of green manufacturing, new manufacturing supported by green finance has been formed.

Digital finance innovation in green manufacturing is mainly reflected in two aspects: on the one hand, new green manufacturing methods such as intelligent green manufacturing, flexible green manufacturing, and virtual green manufacturing are accelerating in popularity. Digital finance penetrates traditional manufacturing, triggers green and digital innovation, and realizes green manufacturing under the digital revolution. On the other hand, the traditional boundaries between green manufacturing and service industries are gradually blurring, and the integration of the two is becoming more and more prominent. In this context, digital technologies are having a disruptive impact on the green manufacturing industry chain, the value chain, and the innovation chain. And, every link of digital innovation has the participation of digital finance. The original factory-based green manufacturing industry will be extended upstream and downstream in the industrial chain into technology development and marketing, increasing the added value of products through digital innovation in science and technology and marketing (Nasreen et al. 2017). In this critical part of the innovation chain, it is a functional linkage model that is oriented towards market demand, with the acquisition of new technologies and product development as the core, linking multiple actors through institutional, organizational, and management innovation and realizing the value added in the whole process of innovation. The essence of digital finance innovation is to reveal the flow, transformation, and value added of knowledge and technology throughout the process, reflecting the synergy, cooperation, and value transfer of multiple participating actors in the whole process. The integration of next-generation information and digital technologies into green manufacturing has had a significant positive effect on industry development and the national economy. Scholars have studied this from different perspectives.

Regarding the definition of digital innovation, Yoo et al. (2010) define digital innovation as the production of new products through a new combination of digital and physical elements based on Schumpeterian innovation theory. Nambisan et al. (2017) propose digital innovation from a value creation perspective to create and continuously change market products, business processes, or business models caused by digital technologies. On the other hand, Edu et al. (2020) propose a definition from the perspective of IT capabilities: the ability to rely on improved IT capabilities to transform an organization's access to new and existing knowledge, skills, customized requirements, new products or service lines, value creation, capabilities, and speed of delivery. These form the basis of digital finance innovation, which consists of two main perspectives: one is that digital finance innovation is mainly about optimizing existing products and increasing added value through services. The other is that digital innovation uses digital technology by companies to optimize various aspects of their business and ultimately improve their performance. In terms of understanding the connotation of digital innovation, Henfridsson et al. (2018) take a structural perspective. They argue that digital innovation is about capturing value by creating connections between different digital resources and that the value space is conceptualized as four layers in the digital system. Along with resource integration and collaborative activities, the link between actors and resources is becoming stronger. Nambisan (2018) states that the relationship between actors and resources in digital innovation can be better understood from an ecosystem perspective. In addition, Yoo et al. (2010) summarize the main characteristics of digital technology (programmability, the homogenization of data, the self-referential nature of digital technology), the main characteristics of digital innovation (convergence and generativity), and the types of digital innovation (distributed innovation and combinatorial innovation). In an empirical study in recent years, Khin and Ho (2018) explored the relationship between digital capabilities and firm performance using digital innovation as a mediating variable, confirming the importance of digital technology and digital orientation in enhancing firm performance. Nasiri et al. (2020) quantified digital innovation in two dimensions, business processes, and market offerings and explored the relationship between digital-related competencies and digital innovation, confirming the importance of digital humanities and collaborative, technological, and innovation competencies.

The main elements of the existing review literature are outlined in Table 1. In general, the theoretical literature on digital finance innovation is gradually improved, but the empirical literature is still in its infancy and has not yet developed a comprehensive scale. In addition, there is a lack of in-depth research into the green manufacturing industry as digital finance innovation is still a young topic that is being explored by academics across disciplines. However, the green manufacturing industry is precious to study as the most widely used and specific industry for digital innovation. Therefore, this study aims to provide an overview of past, present, and future research directions in digital innovation in green manufacturing, using bibliometric methods (Ahmad et al. 2019). The paper is structured as follows: this literature begins with an introduction that introduces the real-life context of digital innovation in green manufacturing, while we compare it with published reviews on related topics and point out the innovative nature of this study. In the second section, we describe this paper's research instruments and 


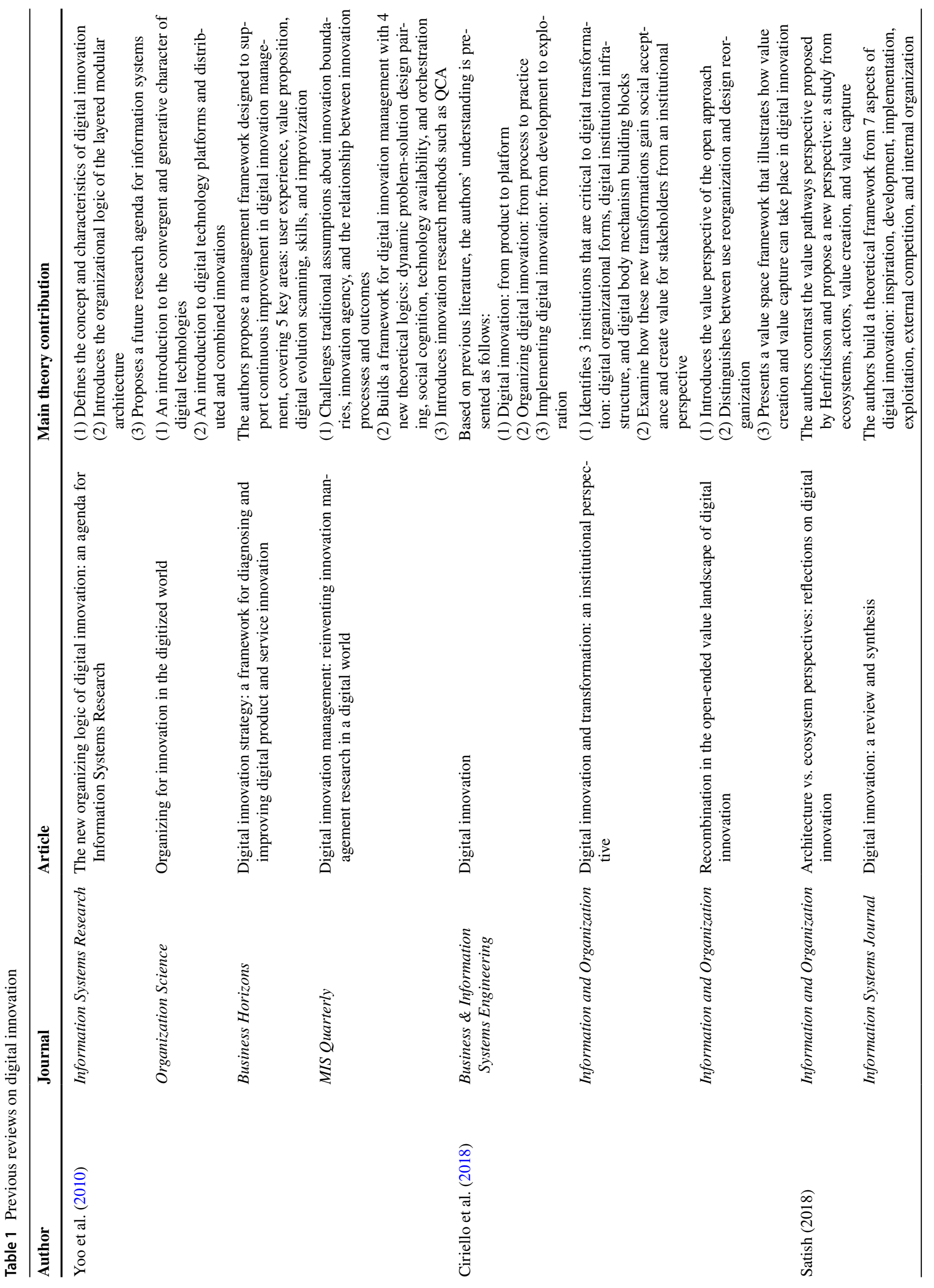


methodology and describe the research design. In the third section, we describe and analyze the bibliometric results, including an analysis of publication trends, journals, authors, institutions, and countries, and a review of the research lineage. In the fourth section, we again use VOSviewer to cluster the literature and refine the core elements of each cluster. In the fifth section, we classify the types of digital finance innovation from the perspective of value creation and distill the paths to digital innovation for green manufacturing companies based on intelligent servitization and collaborative capabilities. Finally, there is a summary and outlook section where we first summarize the conclusions obtained, point out the paper's limitations, and finally make predictions about possible future research directions.

\section{Method}

\section{Bibliometric analysis and software}

Bibliometrics is the interdisciplinary discipline of quantitative analysis of a field of knowledge through mathematical and statistical methods and is a vast body of knowledge that integrates mathematics, statistics, and bibliography. Bibliometrics focuses on describing, evaluating, and predicting the current state of knowledge and trends through the analysis of the number of literature characteristics (e.g., number of publications, number of citations) (Van Raan 1996). Scientific knowledge mapping is a comprehensive analysis method that combines traditional bibliometric methods with modern text mining techniques. The analysis of author cocitations, keyword co-occurrences, and keyword clustering enables us to tap into the research lineage, research hotspots, research frontiers, and collaborative relationships between authors, institutions, and countries in a particular research area, which helps us to grasp the changing trends and academic dialogue on the subject and thus better conduct future research.

Two visual analysis tools for bibliometrics have been chosen for this paper: VOSviewer and HistCite. VOSviewer is a bibliometric and analytical software program for building knowledge graphs developed by Van Eck and Ludo Waltman at the Centre for Science and Technology Studies (CWTS) at Leiden University in the Netherlands. The core principle of the software is to mine "co-occurrence and clustering" based on distances, draw correlation graphs (Rehman et al. 2021), and show the importance of documents, i.e., their interrelationships, through the color, size, and distribution of heavy network nodes (Eck and Waltman, 2010). HistCite is a visual tool for citation chronology. In addition to calculating the frequency of citations and outputting a list of documents, the most crucial feature of HistCite is the generation of citation chronology charts. This can help us find the source literature 
and uncover the succession of citations to show the research lineage under the field (Ahmad et al. 2019). The core idea is to use the Global Citation Score (GCS) and Local Citation Score (LCS) provided by the Web of Science (WoS) database as the leading indicators to measure the impact of the literature for analysis (Garfield 2009).

\section{Research design}

This bibliometric study aimed to locate the most active and influential research areas on digital innovation in manufacturers. We gathered raw data from the WoS database belonging to Thomson Reuters, which contains more than $50,000,000$ publications, more than 22,000 journals, and 151 research areas (Llanos-Herrera and Merigo, 2018). The WoS database is a digital bibliometric platform internationally recognized for reflecting the level of scientific research (Merigó et al. 2015). Among these, SCIE, SSCI, and other citation index databases; Journal Citation Reports (JCR); and ESI fundamental scientific indicators are well known worldwide. By assigning a unit to each author, institution, journal, or country for each publication registered in the WoS, we aimed to provide an overview of the most productive and influential authors, institutions, and countries (Lafont et al. 2020). More specifically, the present study considers bibliographic records obtained from the WoS Core Collection. Regarding the time frame, the research included all publications from 1900 (the beginning of the standard range) to May of 2021 (2021 has not ended during the study).

To perform a search within the WoS Core Collection database, we followed three steps. (1) The keywords are selected to filter the information. Similar to bibliometric approaches performed by other scholars (Magaly et al. 2018), our criteria for these keywords are based on existing review articles mentioned in Table 1. The search string used in the WoS Core Collection database was a combined search to return the most relevant study field in our research area: Topic $=($ digital innovation OR digitization OR digitalization OR Intelligent OR digital finance*) AND Topic = (manufacturer* OR Green-Manufacturing*). (2) Having identified 7152 articles, we then reduced the number of articles to 356 using the following WOS categories: business and management. The document type must be categorized as an article and review to evaluate only research studies (Merigó et al., 2015). (3) The number of results was not exceptionally high; therefore, to ensure the validity of the data, namely the retrieved literature is highly related to our aim topic, the use of different filters was envisaged by manual screening. According to the title and abstract of the article, we eliminated those which did not match the subject, like the researches on banking and insurance. In the end, the search yielded 296 results, which were used to develop the current study. Figure 1 illustrates the documents retrieval process in three steps.

\section{Bibliometric analysis results}

\section{Trend analysis}

The number of publications and the frequency of citations often reflect the history and trends of a subject area and are often seen as an essential indicator of the contribution of scientific research. Based on the literature search results, we plotted the number of publications (Fig. 2) and the frequency of citations (Fig. 3) per year for research on digital finance innovation in green manufacturing. On the one hand, in terms of the number of annual publications, there has been a dramatic increase over the last 20 years, starting to exceed 100 for the first time in 2009 and reaching 1621 in 2020. Of these, the literature focusing on business and management studies shows the same pattern of growth, particularly in the last 5 years, achieving a multiplicative increase from 12 articles in 2016 to 97 articles in 2020. On the other hand, after focusing on 296 papers in the field of business and management, we derive the citation report from WoS, and looking at the annual citation frequency, as shown in Fig. 2, we can find that the citation frequency starts to increase from 2009 and achieves a multiplicative increase from 2018 to 2020. This

Development of keywords for research on digital innovation in manufacturers

Filtering Criteria:

- WoS catogories: Business, Management

- Catalogued as: article, review

- Published time: between 1900 and May 2021

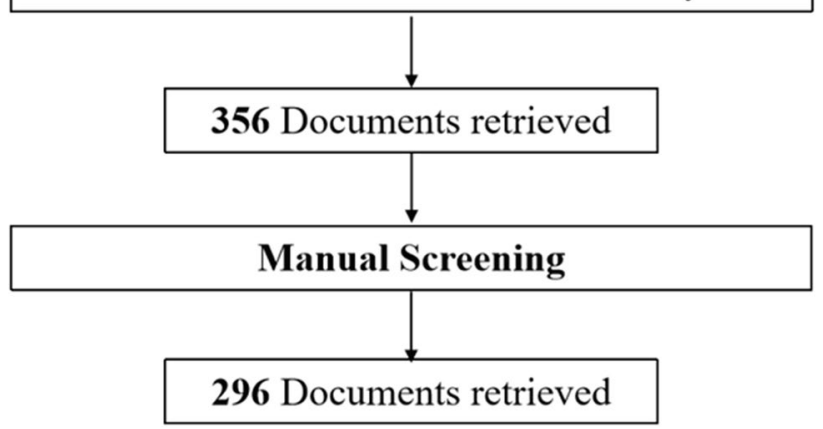

Fig. 1 Documents' collection process 
Fig. 2 Number of publications on "Digital innovation in greenmanufacturers"
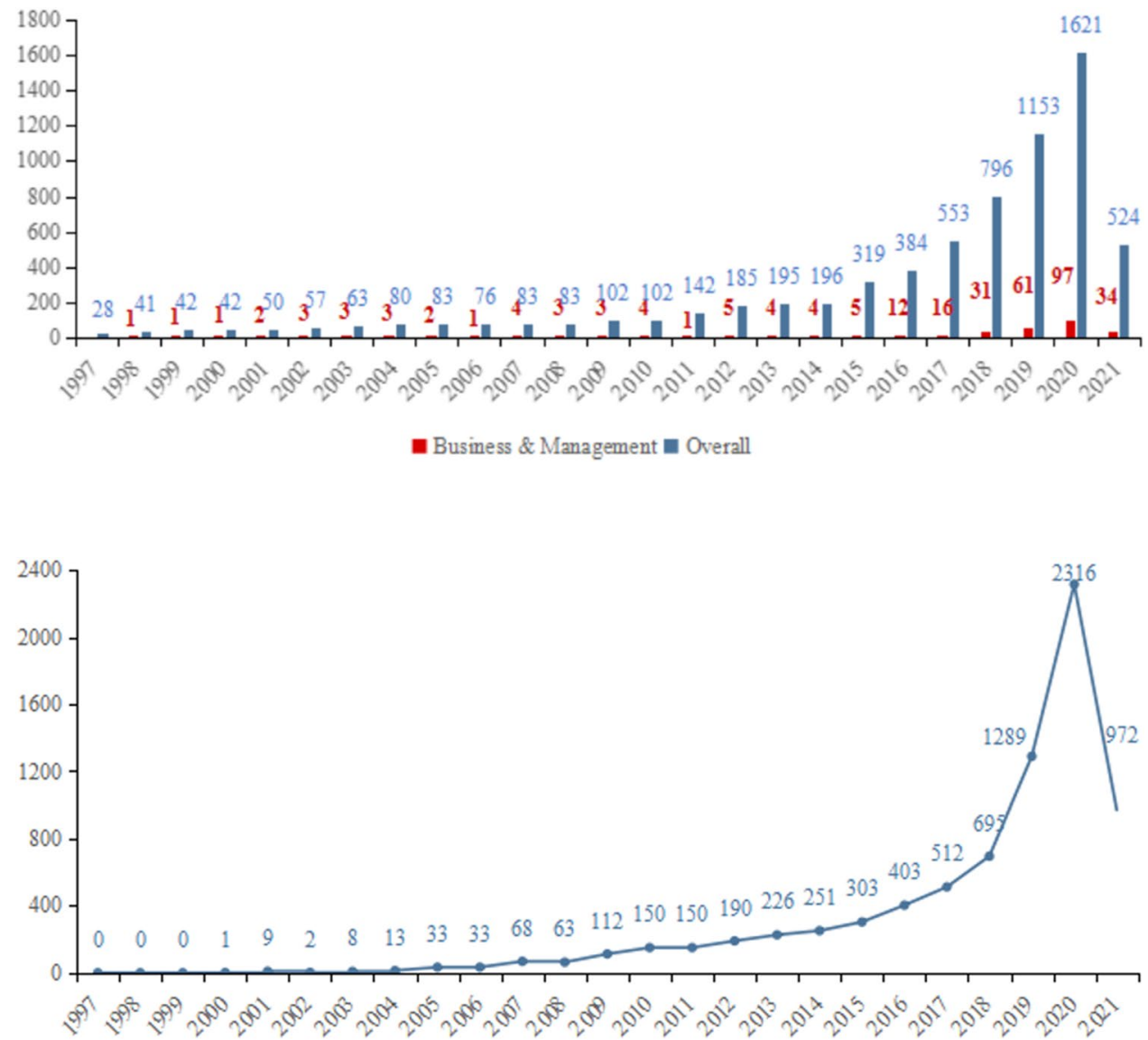

Fig. 3 Number of annual citations represented by China have also seized the opportunities of the times, such as Made in China 2025 released in 2015, which aims to build a green manufacturing powerhouse that will lead the world's green manufacturing development. The strategic changes of the country lead the green manufacturing industry to undergo transformation and upgrading. In this practical context, on the one hand, some scholars use their keen insight to forecast the future development direction of the industry. On the other hand, many scholars have conducted case studies and empirical explorations based on enterprise practices, continuously refining and constructing theoretical frameworks for green manufacturing innovation and verifying and improving these theories through empirical methods to provide theoretical guidance for the digital and intelligent transformation of more enterprises.

\section{Journal analysis}

An analysis of the journals and impact factors of the published literature allows us to determine the main research areas and impact of digital finance innovation in green manufacturing. Table 2 shows the 10 journals with the highest number of publications on the topic of digital finance innovation in green manufacturing, with Journal of Manufacturing Technology Management, a journal focused 
Table 2 Top 10 productive and influential journals

\begin{tabular}{|c|c|c|c|c|c|c|c|c|}
\hline $\mathbf{R}$ & Journals & $\mathbf{T P}$ & $\% \mathbf{P}$ & TLCS & TGCS & IF & 5-IF & $\mathbf{H}$ \\
\hline 1 & Journal of Manufacturing Technology Management & 38 & 12.84 & 64 & 505 & 3.385 & - & 10 \\
\hline 2 & Technological Forecasting and Social Change & 28 & 9.46 & 88 & 1316 & 5.846 & 5.179 & 17 \\
\hline 3 & Industrial Marketing Management & 15 & 5.07 & 43 & 407 & 4.695 & 5.868 & 8 \\
\hline 4 & Journal of Business Research & 11 & 3.72 & 33 & 157 & 4.874 & 5.484 & 7 \\
\hline 5 & International Journal of Operations \& Production Management & 9 & 3.04 & 3 & 43 & 4.619 & 5.676 & 5 \\
\hline 6 & Journal of Business \& Industrial Marketing & 9 & 3.04 & 12 & 47 & 2.497 & 2.713 & 7 \\
\hline 7 & Technology Analysis \& Strategic Management & 9 & 3.04 & 6 & 93 & 1.867 & 2.105 & 5 \\
\hline 8 & Harvard Business Review & 7 & 2.36 & 12 & 1882 & 5.694 & 6.849 & 6 \\
\hline 9 & Research-Technology Management & 7 & 2.36 & 39 & 210 & 2.449 & 3.677 & 3 \\
\hline 10 & Systems Research and Behavioral Science & 7 & 2.36 & 5 & 28 & 0.731 & 1.07 & 3 \\
\hline
\end{tabular}

on green manufacturing management, having the highest number of publications, and Technological Forecasting and Social Change having the highest $\mathrm{H}$ index despite having the second-highest number of publications, which shows the strong influence of this journal in the field of green manufacturing research. All 10 journals are basically of high quality with an IF of 2 or more in terms of impact factor. Among the top 5 journals in terms of the number of articles published, Technological Forecasting and Social Change, Industrial Marketing Management, and Journal of Business Research are all top journals in industrial management, with impact factors above 4 . These four journals account for $31 \%$ of the total number of articles published, indicating that research in this field has a solid theoretical foundation and strong influence. Furthermore, it is clear from the nature of the journal that research into digital finance innovation in green manufacturing is a focus of the technical field and is also of interest to the fields of management, marketing, and information systems.

$R$ rank, $T P$ total publication, $\% P$ percentage, $T L C S$ total local citation score, TGCS total global citation score, IF impact factor 2020, 5-IF 5-year impact factor, $H \mathrm{H}$ index

This paper further refers to by using VOSviewer to couple all journals in the literature for analysis (Fig. 4). The literature coupling analysis reflects the importance of a journal by the literature cited, with larger circles representing journals in the map indicating more significant importance. In Fig. 4, it can be found that Journal of Manufacturing Technology Management, Technological Forecasting and Social Change, Industrial Marketing Management are in the central position, followed by Journal of Business Research, International Journal of Operations \& Production Management, and other journals. The top journals MIS Quarterly and Technovation are also highlighted in the map, and although these two journals have a relatively low volume of publications, they still have a high impact in terms of the citation map. The color of the circles in the map indicates the different clusters, elaborated on later in the content analysis section.

In addition, to visualize the importance that each journal places on this topic, the top 5 journals in terms of the number of articles published and the corresponding number of articles published each year are plotted in a cumulative bar chart (Fig. 5). The graph shows that the Journal of Manufacturing Technology Management and Technological Forecasting and Social Change are the top journals regarding the number of articles published each year. At the same time, the Journal of Manufacturing Technology Management and Technological Forecasting and Social Change both have the highest number of articles published each year. At the same time, Industrial Marketing Management started to focus on this topic in 2020, and the interest of each journal in the topic of digital finance innovation in green manufacturing is increasing year by year.

\section{Country analysis}

Table 3 shows the number of articles published by scholars from different countries, among which the USA has 56 articles, far more than other countries, accounting for $18.92 \%$, followed by Germany, Sweden, the UK, Finland, Italy, and China. This phenomenon is closely related to the accelerated re-industrialization and subsequent development of advanced green manufacturing technologies in developed countries, driven by the new technological and industrial revolutions since the second decade of the twenty-first century. International trends also indicate that the era of high reliance on labor in green manufacturing is coming to an end and that intelligent green manufacturing is leading the development of green manufacturing. The USA was the first to announce a national strategic plan for advanced green manufacturing in 2012, elevating advanced green manufacturing to a national strategy, followed by Germany, France, and the European Union, which also began to deepen the integration 


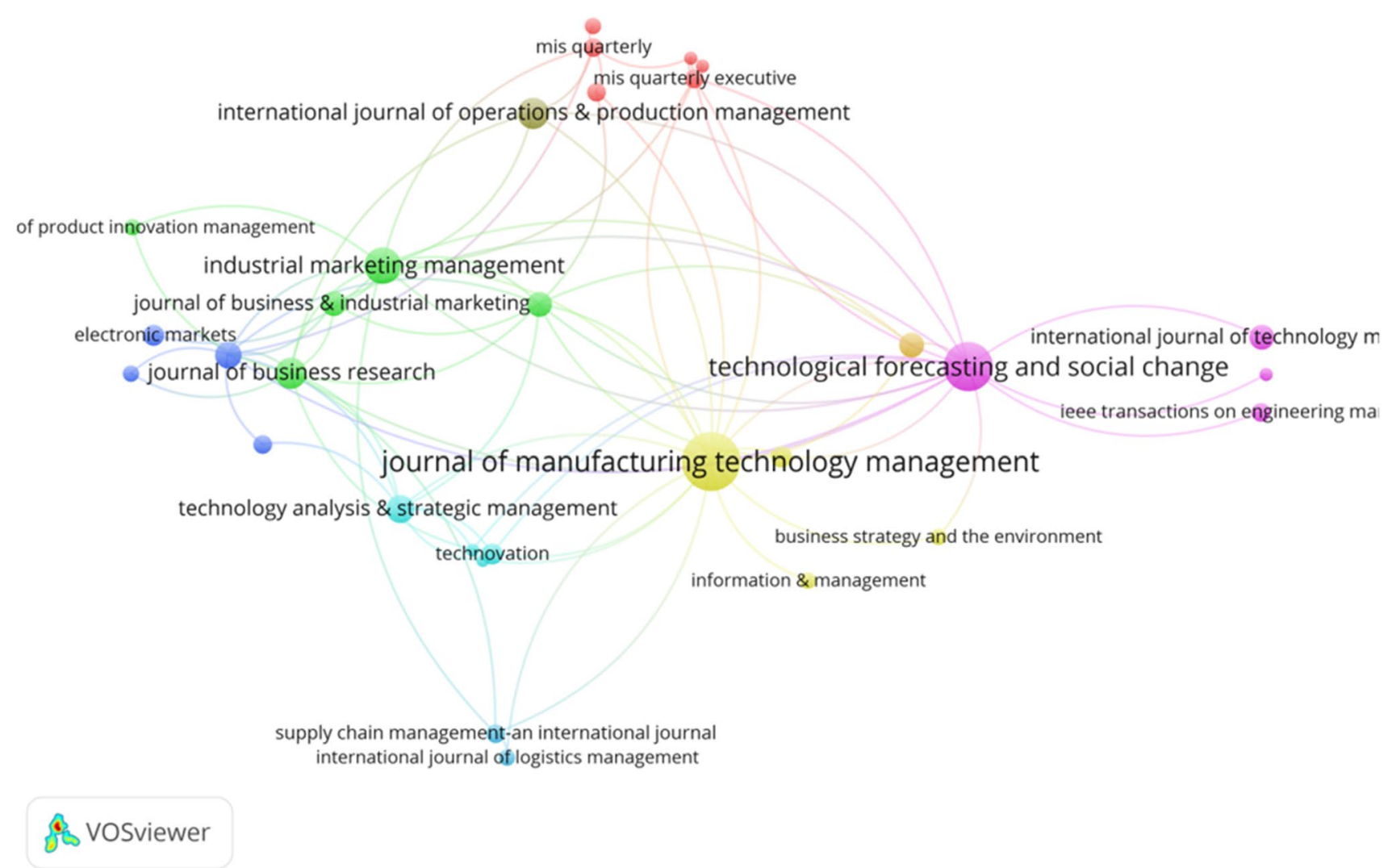

Fig. 4 Map of co-citation analysis based on journals

Fig. 5 Journal-wise number of articles in latest years

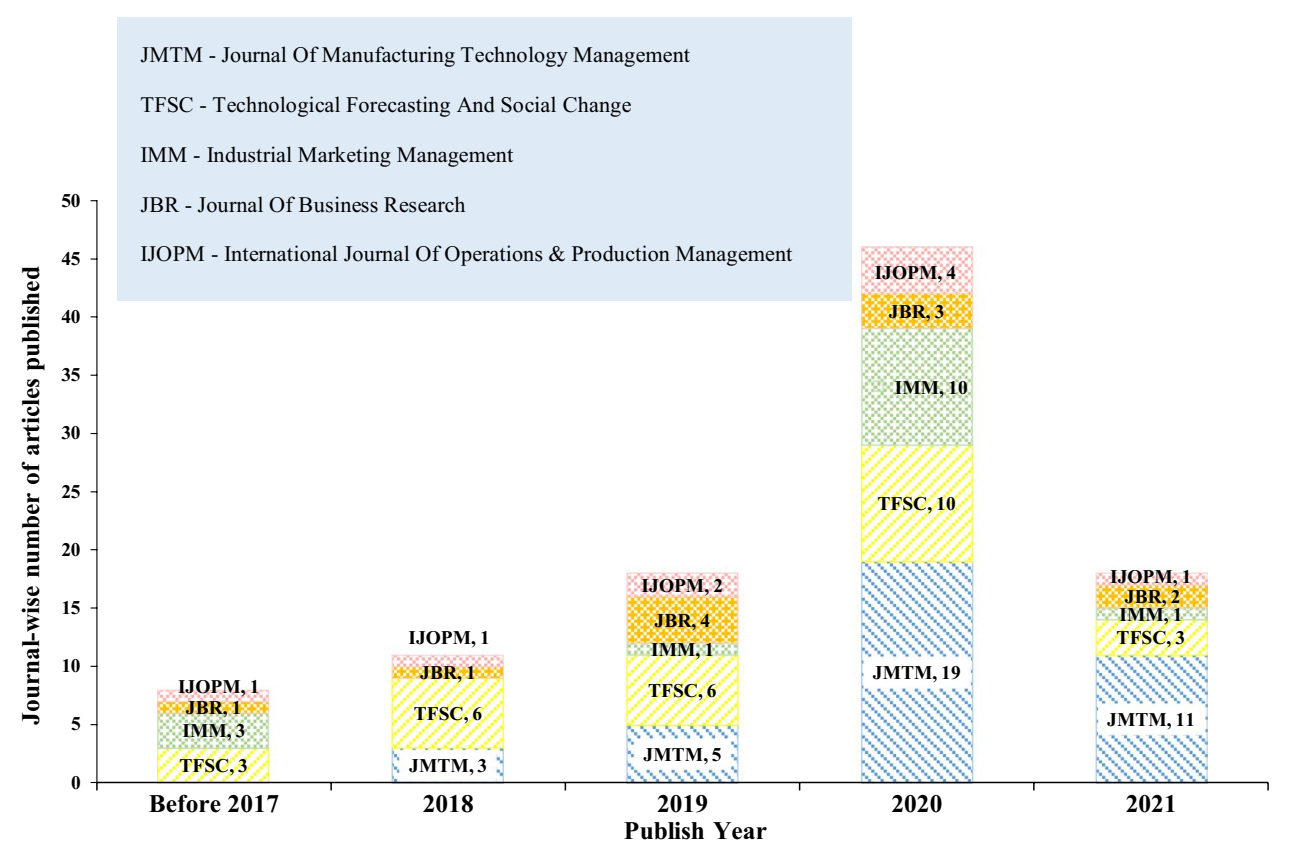

of the network economy with the real economy and promote Internet-supported intelligent green manufacturing production methods in the digital economy era. The USA was the first to begin strategic deployment, which is why it has the highest number of publications under the theme of digital finance innovation in green manufacturing. Overall, the number of articles published in developed countries is significantly higher than that in developing countries and is 
Table 3 Top 10 publishing countries

\begin{tabular}{llllll}
\hline $\mathbf{R}$ & Country & TP & \%P & TLCS & TGCS \\
\hline 1 & USA & 56 & 18.92 & 50 & 1741 \\
2 & Germany & 40 & 13.51 & 84 & 902 \\
3 & Sweden & 34 & 11.49 & 87 & 668 \\
4 & UK & 32 & 10.81 & 44 & 629 \\
5 & Finland & 29 & 9.80 & 83 & 581 \\
6 & Italy & 26 & 8.78 & 27 & 370 \\
7 & People's Republic & 23 & 7.77 & 1 & 138 \\
& of China & & & & \\
8 & Switzerland & 18 & 6.08 & 36 & 304 \\
9 & Spain & 15 & 5.07 & 3 & 408 \\
10 & Brazil & 14 & 4.73 & 25 & 309 \\
\hline
\end{tabular}

also closely related to the progress of strategic deployment in each country.

$R$ rank, $T P$ total publication, $\% P$ percentage, $T L C S$ total local citation score, $T G C S$ total global citation score

In addition, Fig. 6 shows the collaborative relationships between scholars from different countries. It can be seen that co-authorship is prevalent in the USA, Germany, Sweden, the UK, and China, and scholars are actively seeking orchestration with foreign scholars, which effectively breaks the geographical limitation of research and helps to enhance the universality of theories. Based on the number of publications and the frequency with which academics cite the literature in these countries, we can surmise that this orchestration has effectively contributed to the efficiency and quality of research output.

\section{Author and institution analysis}

The authors of the literature influence the field to some extent, especially as scholars with more publications in high-quality journals tend to have keen insight and understanding of the field. Therefore, analyzing highly productive authors and collaborative networks can help us identify core authors, track the series of studies by that author, understand the research lineage of a topic, and capture research hotspots and research frontiers through the research content of the core author's research team. Table 4 shows the top 10 authors and their institutions according to the number of publications. The local citation rate and the global citation rate of each author's publications are also shown. The

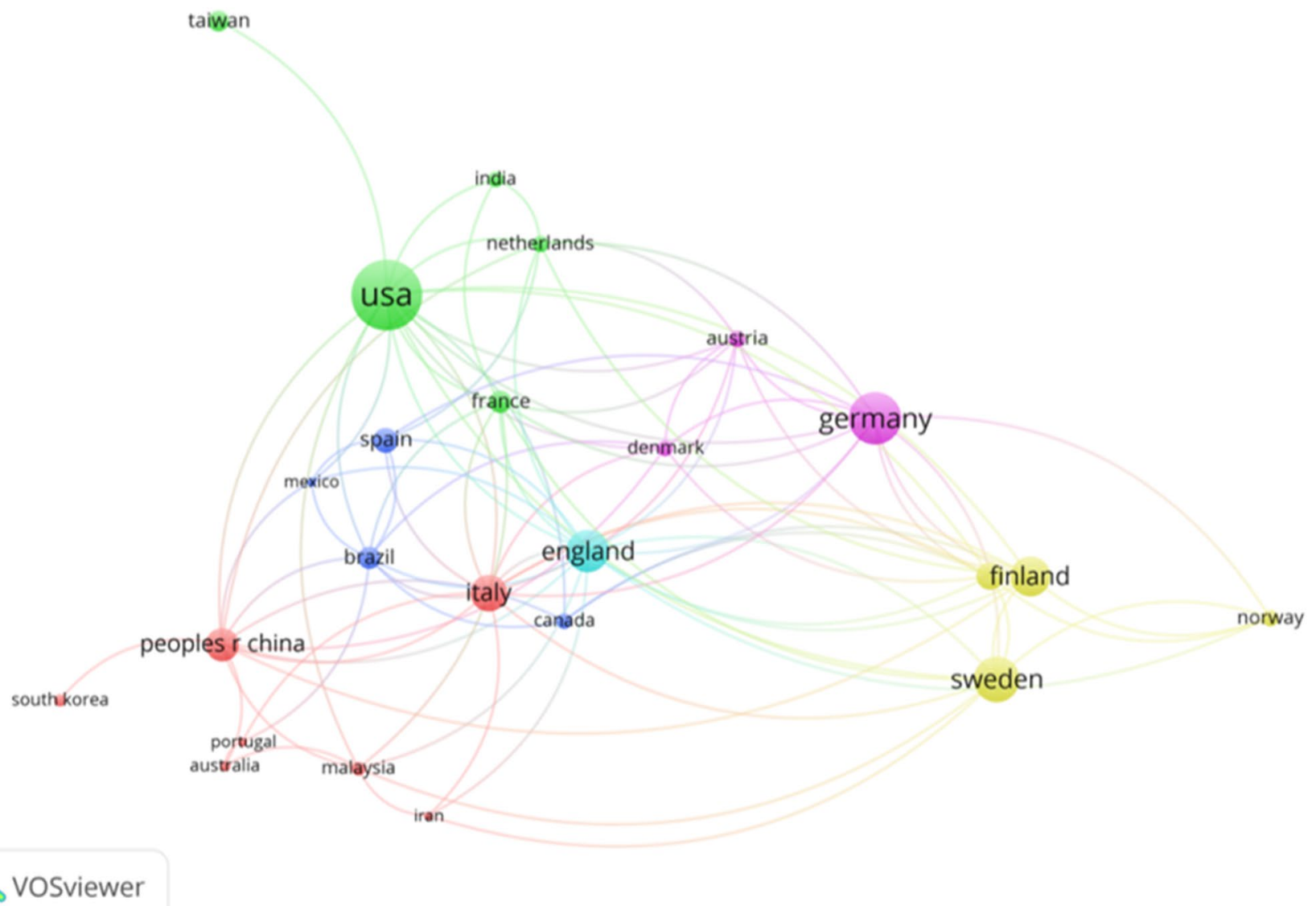

Fig. 6 Map of co-authorship analysis based on countries 
Table 4 Top 5 most productive authors

\begin{tabular}{lllllll}
\hline $\mathbf{R}$ & Author & Institution & TP & \%P & TLCS & TGCS \\
\hline 1 & Parida V & Lulea University of Technology & 14 & 4.80 & 56 & 294 \\
2 & Gebauer H & Linkoping University & 8 & 2.74 & 22 & 109 \\
3 & Kohtamaki M & University of Vaasa & 7 & 2.40 & 27 & 114 \\
4 & Sjodin D & Lulea University of Technology & 5 & 1.71 & 11 & 45 \\
5 & Kowalkowski C & Hanken School of Economics & 4 & 1.37 & 18 & 109 \\
6 & Wincent J & Lulea University of Technology & 4 & 1.37 & 21 & 151 \\
7 & Afum E & Dalian Maritime University & 3 & 1.03 & 1 & 8 \\
8 & Agyabeng-Mensah Y & Dalian Maritime University & 3 & 1.03 & 11 & 193 \\
9 & Ahenkorah E & Regent University & 3 & 1.03 & 16 & 106 \\
10 & Diaz-Chao A & Rey Juan Carlos University & 3 & 1.03 & 1 & 8 \\
\hline
\end{tabular}

No. 1 author in terms of the number of articles published is Parida Vinit, whose research focuses on digitalization, servitization, and value co-creation in green manufacturing companies, with 14 co-authored articles, accounting for $4.8 \%$ of the total number of articles published, and with the highest citation rate. Of these, five have been published in the Journal of Business Research, two in Industrial Marketing Management, two in Research-Technology Management, and one in Technological Forecasting and Social Change. The second most published author is Gebauer Heiko, whose research focuses more on innovation in digital products, processes, and business models, with eight co-authored publications accounting for 2.74 of the total literature. Kohtamaeki Marko and Sjodin D ranked third and fourth, respectively, regarding the number of posts.

$R$ rank, $T P$ total publication, $\% P$ percentage, $T L C S$ total local citation score, $T G C S$ total global citation score
In conjunction with Fig. 7 , it can be seen that Kohtamaeki Marko and Sjodin D were the main collaborators of Parida Vinit and Gebauer Heiko. It is worth noting that Kohtamaeki Marko and Sjodin D have taken on more first author roles, showing that they significantly contribute to the field. In addition, the authorship of Table 4 shows that Parida Vinit, Sjodin D, and Wincent $\mathrm{J}$ are all from the same scientific institution, Lulea University of Technology, which has made a significant contribution and influence in the field of digital innovation in green manufacturing. We have listed the critical literature, publication dates, and journals they have worked on within Table 5 and can see that their research topics include the impact of servitization, digitalization, and related capabilities on corporate performance and business models.

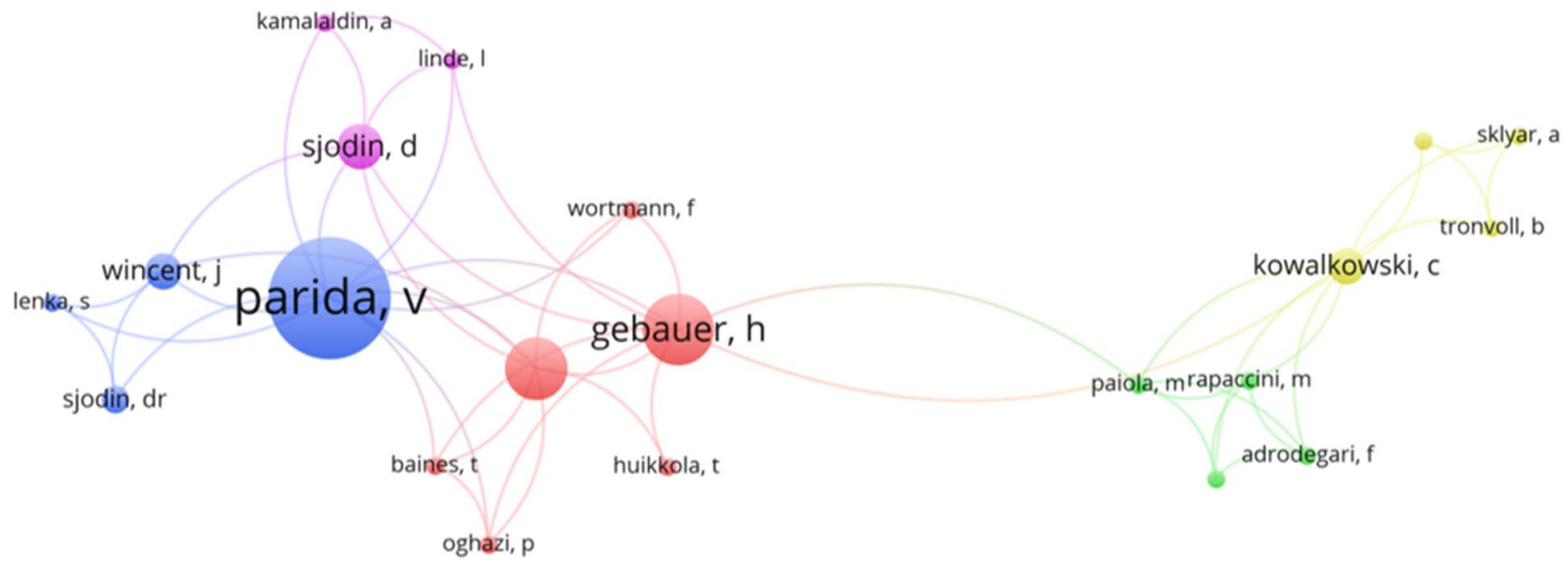

\section{VOSviewer}

Fig. 7 Mapping of co-citation of authors 
Table 5 Major collaborative literature of Parida V, Sjodin DR, and others

\begin{tabular}{|c|c|c|c|}
\hline Year & Author & Title & Journal \\
\hline 2015 & Parida V, Sjodin DR, Lenka S, Wincent J & $\begin{array}{l}\text { Developing global service innovation capa- } \\
\text { bilities: how global manufacturers address } \\
\text { the challenges of market heterogeneity }\end{array}$ & Research-Technology Management \\
\hline 2017 & Lenka S, Parida V, Wincent J & $\begin{array}{l}\text { Digitalization capabilities as enablers of } \\
\text { value co-creation in servitizing firms }\end{array}$ & Psychology \& Marketing \\
\hline 2018 & Sjodin DR, Parida V, Leksell M, Petrovic A & $\begin{array}{l}\text { Intelligent factory implementation and } \\
\text { process innovation: a preliminary matu- } \\
\text { rity model for leveraging digitalization in } \\
\text { manufacturing }\end{array}$ & Research-Technology Management, 2018 \\
\hline 2019 & $\begin{array}{l}\text { Kohtamaki M, Parida V, Oghazi P, Gebauer } \\
\text { H, Baines T }\end{array}$ & $\begin{array}{l}\text { Digital servitization business models in } \\
\text { ecosystems: a theory of the firm }\end{array}$ & Journal of Business Research \\
\hline 2019 & Sjodin D, Parida V, Kohtamaki M & $\begin{array}{l}\text { Relational governance strategies for advanced } \\
\text { service provision: multiple paths to superior } \\
\text { financial performance in servitization }\end{array}$ & Journal of Business Research \\
\hline 2020 & Sjodin D, Parida V, Kohtamaki M, Wincent J & $\begin{array}{l}\text { An agile co-creation process for digital } \\
\text { servitization: a micro-service innovation } \\
\text { approach }\end{array}$ & Journal of Business Research \\
\hline 2020 & Kohtamaki M, Parida V, Patel PC, Gebauer H & $\begin{array}{l}\text { The relationship between digitalization and } \\
\text { servitization: the role of servitization in } \\
\text { capturing the financial potential of digitali- } \\
\text { zation }\end{array}$ & $\begin{array}{l}\text { Technological Forecasting and Social } \\
\text { Change }\end{array}$ \\
\hline 2021 & Burstrom T, Parida V, Lahti T, Wincent J & $\begin{array}{l}\text { AI-enabled business-model innovation and } \\
\text { transformation in industrial ecosystems: a } \\
\text { framework, model and outline for further } \\
\text { research }\end{array}$ & Journal of Business Research \\
\hline
\end{tabular}

\section{Article analysis}

In order to identify the lineage and focus of research on digital finance innovation in green manufacturing, this study chose LCS as a measure of the importance of the literature. It used HistCite to identify the critical literature and the cross-citation relationships between the literature. Table 6 lists the top 25 papers, authors, journals, year of publication, and the number automatically generated by the software. In addition, the citation chronology chart based on LSC metrics is the most essential and distinctive visualization feature of HistCite compared to other citation bibliometric software programs. The citation chronology chart allows us to visualize the horizontal and vertical exchange between the literature under the field. Figure 6 shows the knowledge mapping of the 25 most frequently cited documents selected according to the LCS metrics. Each circle in the diagram represents one document, the size of the circle is positively correlated with the number of citations, and the arrow points to indicate the citation relationship between the documents, with the arrow pointing to the cited document and the end of the arrow to the cited document.

In Fig. 6, longitudinally, the 25 key papers are spread over the years 1999-2019, with an increasingly dense vein of citation relationships over the last 5 years, indicating increasing research activity in the field. In order to present the research content of each node more concisely and clearly, we have marked the titles of the literature near the nodes and distinguished the keywords in the titles with different colors. It can be found that the keywords in the title present the following four main categories: orange for Industry 4.0, IoT; red for servitization, business models, value creation, etc.; blue for dynamic capabilities, innovation capabilities, technological capabilities, etc.; and green for supply chain, relationship management, etc.

\section{Before 2015: laying the theoretical foundations for servitization}

As shown in Fig. 6, the red themes (servitization, service innovation, etc.) have always been the focus of research in these 20 years, and most of the literature with a high number of citations in the graph is also related to this branch of the theme. In addition, the pre-2015 literature provides a solid theoretical foundation and inspiration for the wealth of research that followed. On the one hand, scholars have deepened their research on the servitization of green manufacturing vertically, step by step, from servitization models to servitization strategies to digital product-service systems to the critical competencies required for servitization. On the other hand, scholars have also tried to derive new research perspectives horizontally. 
Table 6 Top 40 most cited publications

R Date/author/journal/year LCS GCS

1 110. Ghobakhloo M

The future of manufacturing industry: a strategic roadmap toward Industry 4.0

Journal of Manufacturing Technology Management, 2018

2 90. Coreynen W, Matthyssens P, Van Bockhaven W

Boosting servitization through digitization: pathways and dynamic resource configurations for manufacturers Industrial Marketing Management, 2016

3 74. Lerch C, Gotsch M

Digitalized product-service systems in manufacturing firms: a case study analysis Research-Technology Management, 2015

4 122. Muller JM, Buliga O, Voigt KI

Fortune favors the prepared: how SMEs approach business model innovations in Industry 4.0

Technological Forecasting and Social Change, 2018

5 43. Allmendinger G, Lombreglia R

Four strategies for the age of intelligent services

Harvard Business Review, 2005

6 129. Li L

China's manufacturing locus in 2025: with a comparison of "Made-In-China 2025" and "Industry 4.0" Technological Forecasting and Social Change, 2018

7 92. Lenka S, Parida V, Wincent J

Digitalization capabilities as enablers of value co-creation in servitizing firms Psychology \& Marketing, 2017

8 164. Kohtamaki M, Parida V, Oghazi P, Gebauer H, Baines T

Digital servitization business models in ecosystems: a theory of the firm

Journal of Business Research, 2019

9 165. Sklyar A, Kowalkowski C, Tronvoll B, Sorhammar D

Organizing for digital servitization: a service ecosystem perspective

Journal of Business Research, 2019

10 31. Wise R, Baumgartner P

Go downstream: the new profit imperative in manufacturing

Harvard Business Review, 1999

11 73. Parida V, Sjodin DR, Lenka S, Wincent J

Developing global service innovation capabilities: how global manufacturers address the challenges of market heterogeneity Research-Technology Management, 2015

12 137. Frank AG, Mendes GHS, Ayala NF, Ghezzi A

Servitization and Industry 4.0 convergence in the digital transformation of product firms: a business model innovation perspective

Technological Forecasting and Social Change, 2019

13 138. Nascimento DLM, Alencastro V, Quelhas OLG, Caiado RGG, Garza-Reyes JA, et al.

Exploring Industry 4.0 technologies to enable circular economy practices in a manufacturing context: a business model proposal

Journal of Manufacturing Technology Management, 2019

14 77. Bogers M, Hadar R, Bilberg A

Additive manufacturing for consumer-centric business models: implications for supply chains in consumer goods manufacturing

Technological Forecasting and Social Change, 2016

15 107. Hasselblatt M, Huikkola T, Kohtamäki M, Nickell D

Modeling manufacturer's capabilities for the internet of things

Journal of Business \& Industrial Marketing, 2018

16 113. Sjodin DR, Parida V, Leksell M, Petrovic A

Intelligent factory implementation and process innovation: a preliminary maturity model for leveraging digitalization in manufacturing

Research-Technology Management, 2018

17 102. Kiel D, Arnold C, Voigt KI

The influence of the industrial internet of things on business models of established manufacturing companies - a business level perspective

Technovation, 2017 
Table 6 (continued)

R Date/author/journal/year LCS GCS

18 123. Reischauer G

Industry 4.0 as policy-driven discourse to institutionalize innovation systems in manufacturing Technological Forecasting and Social Change, 2018

19 66. Holmstrom J, Partanen J

Digital manufacturing-driven transformations of service supply chains for complex products Supply Chain Management-An International Journal, 2014

20 147. Sjodin D, Parida V, Kohtamaki M

Relational governance strategies for advanced service provision: multiple paths to superior financial performance in servitization

Journal of Business Research, 2019

21 157. Horvath D, Szabo RZ

Driving forces and barriers of Industry 4.0: do multinational and small and medium-sized companies have equal opportunities? Technological Forecasting and Social Change, 2019

22 170. Muller JM

Business model innovation in small- and medium-sized enterprises strategies for Industry 4.0 providers and users Journal of Manufacturing Technology Management, 2019

23 65. Smith DJ

Power-by-the-hour: the role of technology in reshaping business strategy at Rolls-Royce Technology Analysis \& Strategic Management, 2013

24 163. Raddats C, Kowalkowski C, Benedettini O, Burton J, Gebauer H

No. 31 paper by Wise and Baumgartner (1999) is published in the Harvard Business Review, where the authors argue that green manufacturing success is no longer based on producing products but on providing services that capture the profits of customers at the end of the value chain, and that intelligent green manufacturing is empowering this new business model. The authors suggest that manufacturers redefine the value chain, think about green manufacturing strategies and vertical integration, and propose four service-oriented business models: embedded service, comprehensive services, integrated solutions, and distributed control. This literature emphasized the importance of servitization in green manufacturing firms and laid the theoretical foundation for later research by scholars investigating how green manufacturing industries can use digital and intelligent technologies to achieve serviced innovation and improve firm performance. After a gap of 5 years, Allmendinger and Lombreglia (2005) published No. 43 article in Harvard Business Review, proposing four business strategies for intelligent servitization: (1) embedded innovator continues to sell bundled services embedded in previous products, remaining product-centric; (2) the solutionist offers high-valued services related to the original product, providing value to the customer by expanding the range of services; (3) the aggregator focuses on data mining, enhancing the company's ability to gain insight into opportunities through the data collection and centralized processing and analysis capabilities of the control system; and (4) the synergist pursues synergy by collaborating with other devices to contribute more valuable data and information. These four intelligent servitization strategies provide direction for the servitization transformation of green manufacturing companies in the digital intelligence era. Ten years later, Lerch and Gotsch (2015) published No. 74 paper describing the transformation path of companies based on the type of digital components and the type of services: manufacturer-IT-based service provider-pure digital service provider, providing digital (PSS). Moreover, the case study outlines three types of digital productservice systems (PSS): intelligent service delivery, intelligent product optimization, and digital brain. In the same year, core author Parida et al. (2015) and others published literature No. 73, which builds on the previous work to explore in-depth the necessary capabilities for companies to pursue servitization innovation from the perspective of corporate capabilities, summarizing four key capabilities: developing customer insights, integrating global knowledge, creating global service offerings, and digital building capabilities. Ultimately, it is emphasized that service innovation in the digital era requires green manufacturing companies to strengthen their interaction with external partners and customers, integrate internally across departments, and fully integrate internal and external resources. 


\section{Beyond 2015: theoretical construction and practical exploration in the era of Industry 4.0}

The proliferation of literature after 2015 thoroughly cites the previous literature and begins to show three main branches: (1) a focus on the relationship between servitization, business models, and value creation in green manufacturing; (2) the critical competencies needed for digital innovation in green manufacturing; and (3) a focus on supply chain management and sustainability in green manufacturing in the context of digital innovation.

In 2016, Bogers et al. (2016) in literature No. 77 focused on the impact of digital green manufacturing technologies (additive green manufacturing, rapid prototyping, and $3 \mathrm{D}$ printing) on the logical shift in green manufacturing business models, where the authors captured that the supply chain in green manufacturing began to shift from centralized to decentralized and business models became more open, i.e., from being centered on the production of goods to being centered on the consumer. The three papers in Fig. 8 that appeared in 2017 looked at the impact of IoT on green manufacturing business models (\#102), the facilitative relationship between digitization and servitization (\#90), and the capabilities required for value co-creation (\#92). Notably, in paper No. 90, Coreynen et al. (2016) explore three paths of servitization that green manufacturing firms can achieve through dynamic resource allocation in different digital contexts: industrial, commercial, and value servitization. Industrial servitization means that suppliers gain new knowledge by optimizing their internal business processes and translate it into value-added services for their customers. The commercialization of services means that green manufacturing companies develop customer-facing digital platforms to capture customer needs and enhance product innovation by bridging front-end and back-end processes and harnessing customer knowledge. Value servitization refers to creating new digital products using a more dynamic, disruptive, and innovative business model by leveraging integration capabilities. This is in contrast to the servitization paths proposed in papers No. 31 and No. 43, where the authors no longer limit themselves to the types of services that green manufacturing can provide, but rather refine different path options for the servitization of green manufacturing in the digital context, from the perspective of the different stages of the enterprise's production process and value creation with other subjects, which reflects the inheritance and development of the theory. Since 2018 and 2019, various literatures have not only enriched their research methods but also worked on new perspectives, based on adequate citations of previous literature, addressing the issue of digital innovation in the context of Industry 4.0 (Nos. 110,122,123,107, and 129), the issue of relational governance in digital finance innovation (Nos.

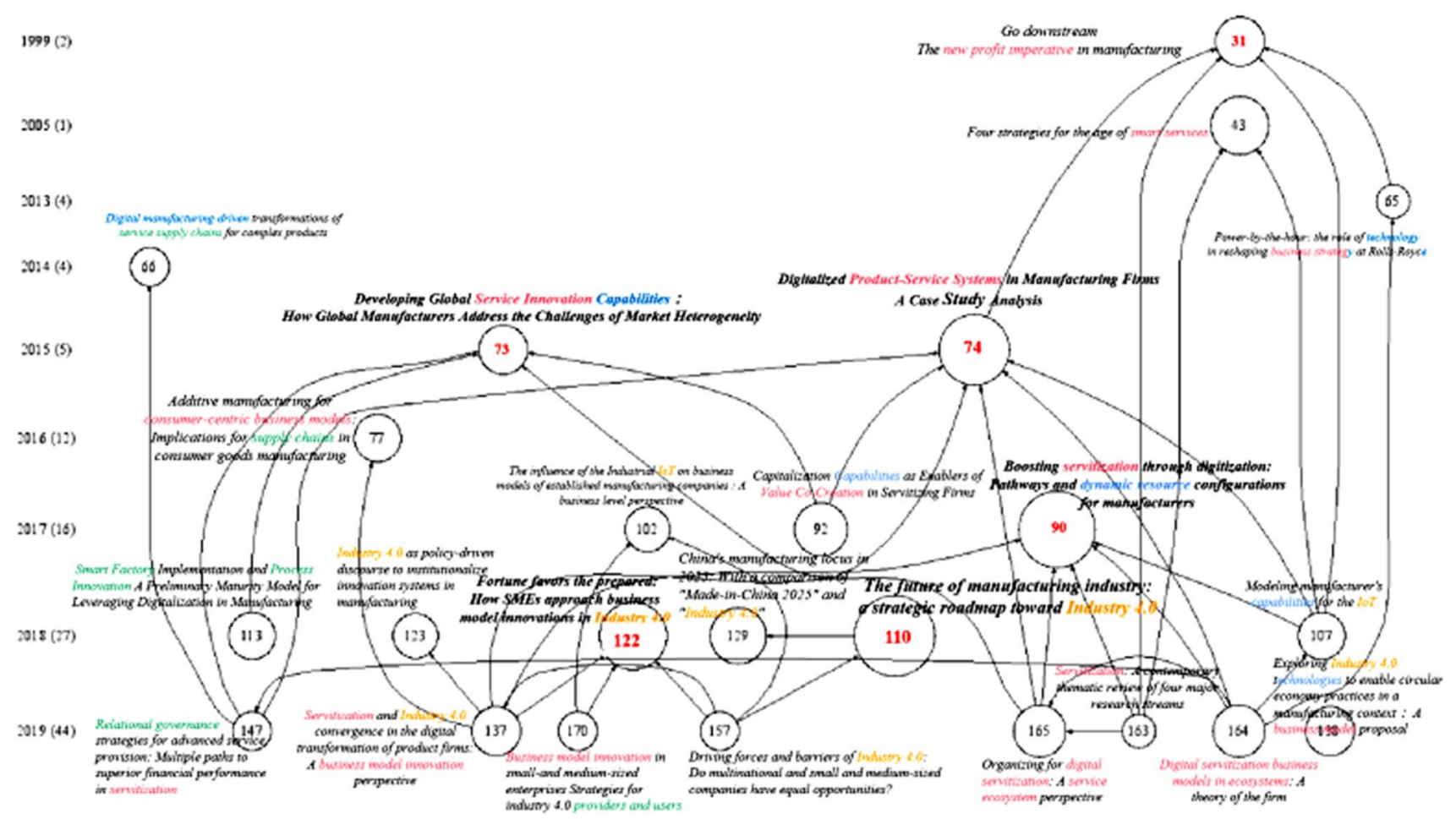

Fig. 8 Article citation relationship 
147 and 170), and the ecosystem of digital. The servitization phenomenon (Nos. 164 and 165) is examined.

This section focuses on the citation relationships of the critical literature to find the lineage of research on digital innovation in green manufacturing. In the next section, we will use VOSviewer to conduct an econometric analysis of the literature titles, abstracts, and keywords to find clusters of research under the topic and explain specifically the main elements of each research cluster.

\section{Content analysis}

In order to find the branches of research under digital finance innovation in green manufacturing, we used the function of VOSviewer text analysis to perform a textual analysis of the titles and abstracts of the literature and visualize their network relationships (Fig. 9). At the same time, overlay visualization (Fig. 10), which reflects temporal changes, was plotted according to the starting time of the appearance of each keyword.

\section{Cluster 1 (red): digital finance innovation, servitization, and business model}

The keywords in cluster 1 consist mainly of the words corresponding to the yellow and red nodes. Table 7 shows all the keywords under this cluster, as well as the frequency of each keyword in conjunction with other keywords (total link strength), the frequency of the keyword itself (occurrences), and the average number of citations (avg. citations). According to Table 7, this cluster focuses on digital finance innovation, servitization (service, servitization, digital servitization, Intelligent service), and business models (new business model, business model innovation, value creation, value proposition, ecosystem, competitiveness). Meanwhile, according to Fig. 10, it can be seen that studies on the topic of products, suppliers, services, and consumers start the earliest, showing the darkest blue,

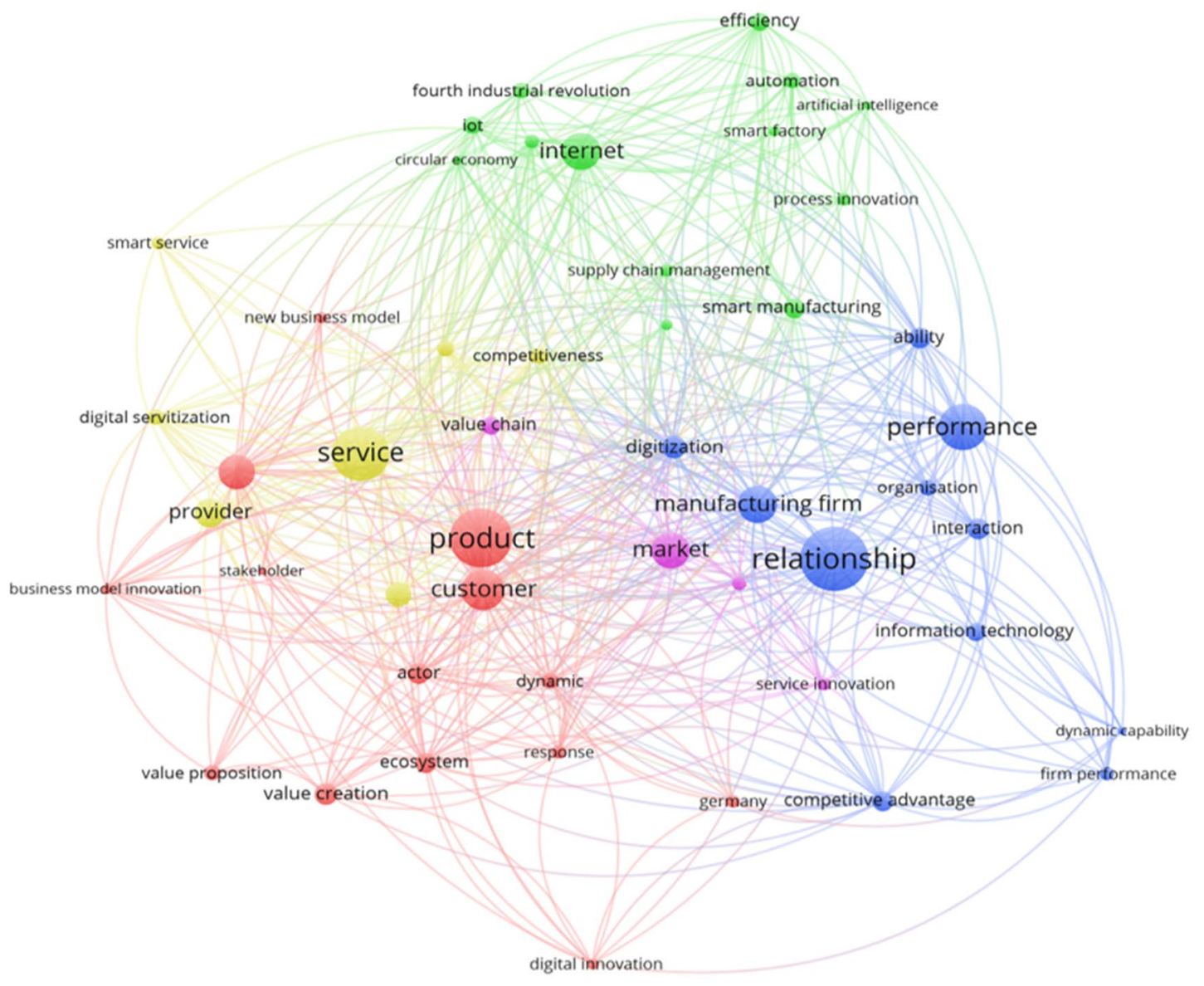

Vosviewer

Fig. 9 Network visualization of keywords 


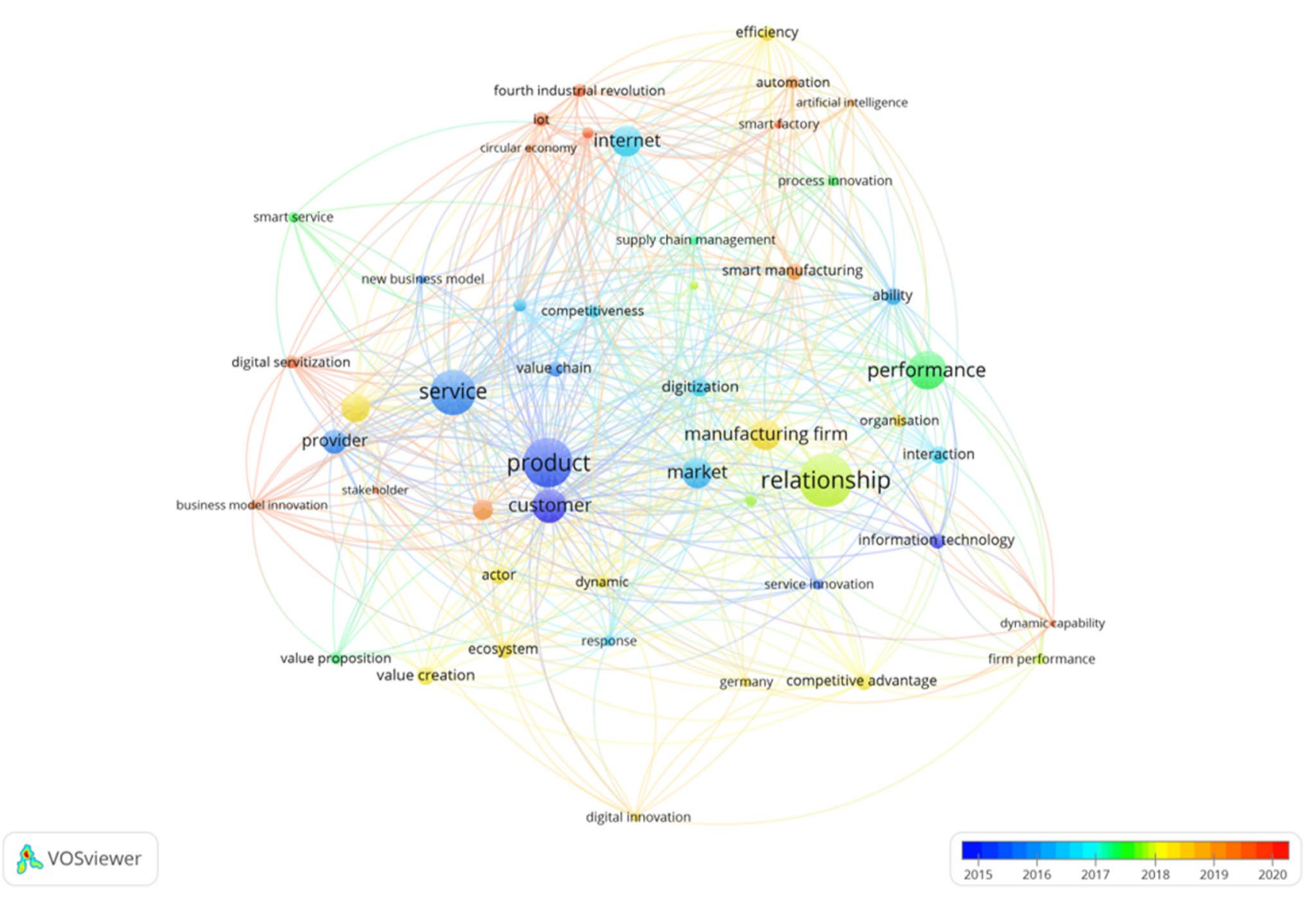

Fig. 10 Overlay visualization of keywords

followed by studies on ecosystems, value co-creation, and participants, which start to appear in yellow and green. In recent years, the hot topics of research have been the digitalization of services and business model innovation. These keywords are shown in red on the map and are closely related to the trends in green manufacturing, which, in the early years, focused more on the production of products and then began to focus on the relationship with suppliers and consumers. With the advancement of the servitization strategy, an ecosystem is gradually forming between the green manufacturing industry and its upstream and downstream, co-creating value with multiple entities and continuously reshaping business models. In recent years, digital and intelligent technologies have led to the convergence of digitization and servitization. From the back end of green manufacturing, companies can enhance operational performance and improve production processes through digital technologies, such as automation. The digitalization of the front end can then better enable multi-entity value co-creation by sharing information between the customer and the supply side (Coreynen et al. 2016), thus continuously promoting the intelligent transformation of green manufacturing.
Under this cluster, scholars have applied different theoretical lenses to dissect value creation in digital finance innovation in green manufacturing. (1) Under the product-led logic, value creation revolves around exchange value, with green manufacturing companies more concerned with producing and acquiring products. In the process of exchange, services are defined by green manufacturing companies as an addition to the product, the understanding of which depends on the product itself and its production and delivery processes. Corporate innovation at this point comes mainly from supplier capabilities, diffusing from internal to external sources. (2) With the development of service marketing, the customer-centric marketing paradigm has advanced the evolution of the service paradigm, and products and services are gradually being differentiated. In the service-dominant logic proposed by Vargo et al., service is corporate competitiveness achieved in terms of behavior, process, and performance for the mutual benefit of stakeholders, where value is co-created by the customer and the company; i.e., the customer is involved in the production process of value. At this point in the value relationship and exchange value, use value also becomes a concern for the firm, and the innovation orientation of the firm begins to spread from external 
Table 7 The keywords of cluster 1

\begin{tabular}{lllll}
\hline Cluster & Label & $\begin{array}{l}\text { Total link } \\
\text { strength }\end{array}$ & Occurrences & Avg. citations \\
\hline 1, red and yellow & Service & 199 & 50 & 62.98 \\
& Product & 178 & 56 & 64.03 \\
& Customer & 143 & 35 & 62.37 \\
& Business model & 112 & 28 & 48.17 \\
Provider & 92 & 23 & 35.56 \\
Servitization & 77 & 18 & 28.72 \\
Value creation & 65 & 16 & 30.37 \\
Actor & 61 & 15 & 24.26 \\
Ecosystem & 55 & 14 & 27.21 \\
Digital servitization & 45 & 10 & 30.2 \\
Response & 45 & 9 & 17.66 \\
Value proposition & 40 & 10 & 18.1 \\
Dynamic & 38 & 10 & 23.9 \\
Boundary & 36 & 10 & 22.1 \\
Intelligent service & 35 & 8 & 29.25 \\
Competitiveness & 34 & 11 & 8 \\
Business model innovation & 32 & 6 & 49.33 \\
Germany & 23 & 8 & 36.25 \\
Stakeholder & 23 & 5 & 5 \\
New business model & 21 & 7 & 127.2 \\
Digital innovation & 20 & 7 &
\end{tabular}

consumers to internal ones (Grieger and Ludwig 2019). In a service-led logic, green manufacturing companies can benefit from orchestration with different players in a network of players to enhance their digital finance innovation capabilities. In addition, green manufacturing companies digitize the assets of buyers and suppliers through the integration of machines, algorithms, information networks, etc., to achieve resource liquefaction and create value by fully mobilizing the resources of internal and external players to come up with new value propositions. Finally, green manufacturing companies transform customer engagement into corporate innovation capabilities by integrating resources in informal customer interactions. In this process, digital technologies need to be matched with a firm's ability to integrate and collaborate resources to stimulate digital innovation (Goduscheit and Faullant 2018). (3) In system-led logic, value creation is derived from the interaction between products and services and the scenarios in which they are located, and corporate innovation is primarily interactive and systemic. Although service ecosystems emphasize the process of interaction and orchestration between multi-subject participants and in-service ecosystems, integration within green manufacturing firms plays a vital role in the digital finance innovation of firms. Intelligent products are equipped with monitoring, control, optimization, and autonomy functions, thus empowering companies to provide intelligent services in terms of behavior, processes, and performance. An intelligent service system is a concept that builds on intelligent products and intelligent services and refers to a system with intelligent products that integrate the resources and activities of relevant participants as boundary objects. Increasingly, green manufacturing companies are building intelligent service systems to make the transition from providing integrated solutions to providing modular solution businesses (Rajala et al., 2018) and providing intelligent services to providing platforms. This places new demands on companies' IT capabilities, platform-related capabilities, and relationship management capabilities (front-end consumers, platform providers, and back-end service providers). The technology platform strategies of green manufacturing companies provide new avenues for orchestrating multi-actor resources in the ecosystem. The ecosystem revolves around a platform core that is simultaneously stable and homogeneous to respond to highly variable market demands using the standardized components of the platform. (4) In the theory of the firm, scholars have used resource-based view, power dependency approach, organizational identity, and transaction cost approach theories to gain insight into the dynamics of corporate decision-making in the process of digital servitization. As the boundaries of a company change from product supplier $\rightarrow$ industrializer $\rightarrow$ integrated solution provider $\rightarrow$ results provider $\rightarrow$ platform provider, the competencies required, the voice in the chain, organizational identity, investment, and the business environment are all 
changing. Furthermore, digital innovation makes it necessary for companies to iterate their business models and coordinate the business models of other players in the ecosystem. (5) Under the availability theory, green manufacturing companies can perceive the characteristics of their strategic goals and IoT technologies, perceive the match between the two through technology availability, and thus explore the opportunities for action in the technology to achieve their corporate goals. Differences in firms' perceived capabilities also bring about differences in how they use digital technologies for innovation and outcomes at different stages. In the transformation of green manufacturing companies, servitization and Industry 4.0 are the two dominant trends. The former is driven by the demand side and focuses on adding value to the customer, while the latter is driven by technology and focuses on adding value to the green manufacturing process. Therefore, developed a conceptual framework linking servitization and Industry 4.0, matching nine ways of digital innovation for green manufacturing firms based on three levels of servitization (smoothing, adaptation, and replacement) and three levels of digitization (low, medium, and high). The theory of availability provides a reasonable explanation for the rationality of the framework; i.e., firms use different features of digital technology at different stages to match the level of service and ultimately achieve digital innovation at each stage of the firm's life (Frank et al. 2019). (6) In the business model theory, scholars have focused on the fact that green manufacturing firms are revolutionizing their business models through digital technologies (e.g., artificial intelligence, 3D printing) (Burstrm et al. 2021). Some scholars have focused on the profitability of business models, such as Barua et al. (2004), who demonstrated empirically that traditional firms are using the Internet to change the way they align value with stakeholders to improve corporate performance. Gebauer et al. (2020) found through a case study that the business models of green manufacturing companies went through three dynamic stages of development, enhancing products, creating customer value, and integrating product portfolios to increase corporate revenues under a "hardware+" logic and a platform logic, respectively. Another group of scholars focused on the value creation network of business models and studied the impact of Industry 4.0 on the business models of green manufacturing companies in terms of value creation. For example, Kiel et al. (2017) found that the degree of impact of the industrial internet of things (IIoT) on the business models of green manufacturing firms was in the following order: value structure, value proposition, relationships, core competencies, partnerships, cost structure, channels, consumers, and revenue. Subsequently, Müller et al. (2018) revealed the impact of the three dimensions of Industry 4.0 (advanced digitalization of processes, Intelligent green manufacturing, and supplier-customer relationships within the value chain) on the three dimensions of the business model (value creation, value delivery, and value capture) aspects. They ranked them in order of impact: essential resources, value proposition, partners, revenue, cost, activity, and channel (Müller, 2019). Also draws consistent conclusions regarding critical partners, activities, resources, value proposition, relationships, costs, and revenues when analyzing the most advanced business models in the construction industry. When business models break through the boundaries of individual firms and the value logic shifts to a consumer-centric approach, green manufacturing firms are more likely to achieve open-mode innovation through collaboration and synergy in the ecosystem and thus optimize their business models in four ways: efficiency, complementarity, lock-in, and innovation (Bogers et al. 2016). The value logic has also changed (from mass production $\rightarrow$ mass customization $\rightarrow$ personalized production).

\section{Cluster 2 (blue): digital finance innovation, dynamic capability, and performance}

The keywords in cluster 2 consist mainly of the keywords corresponding to the blue and purple nodes. Table 8 shows specifically the keywords under this cluster, as well as the frequency of each keyword in conjunction with other keywords (total link strength), the frequency of the keywords themselves (occurrences), and the average number of citations (avg. citations). According to Table 8, this cluster focuses on digital innovation (digitization, information technology), corporate capability (ability, dynamic capability), and corporate performance and digital finance (performance, firm performance). At the same time, according to Fig. 10, the research on IT and service innovation starts first, with the darkest blue color. This is followed by studies on marketing, integration, and datafication, which appear in sky blue. In recent years, the hot topics of research have been corporate performance, competitive advantage, and dynamic capabilities, with these keywords appearing in yellow and red on the map. This indicates that green manufacturing companies are increasingly recognizing that technological innovation alone is not enough. They need to match the corresponding corporate capabilities to transform their resource and technological advantages into competitive advantages and thus achieve the ultimate goal of improving corporate performance. Therefore, in recent years, scholars have gradually started to explore what new competencies companies need to have in the context of digital servitization (e.g., digital competencies, intelligent competencies, orchestration competencies, platform competencies).

Further reading of the literature in cluster 2 reveals that there is already literature examining how different competencies of green manufacturing firms influence firm 
Table 8 The keywords of cluster 2

\begin{tabular}{lllll}
\hline Cluster & Label & $\begin{array}{l}\text { Total link } \\
\text { strength }\end{array}$ & Occurrences & Avg. citations \\
\hline 2, blue and purple & Relationship & 200 & 63 & 21.87 \\
& Performance & 133 & 41 & 27.78 \\
& Manufacturing firm & 130 & 31 & 21 \\
& Market & 99 & 30 & 26.43 \\
& Digitization & 66 & 17 & 78.59 \\
Ability & 52 & 15 & 39.93 \\
& Interaction & 52 & 15 & 48.67 \\
Competitive advantage & 46 & 14 & 10.14 \\
& Service innovation & 43 & 8 & 20.38 \\
Value chain & 42 & 13 & 74.31 \\
Firm performance & 39 & 9 & 50.11 \\
Information technology & 39 & 13 & 50.46 \\
Organization & 32 & 11 & 5.45 \\
China & 19 & 9 & 35.67 \\
Dynamic capability & 14 & 5 & 2.6 \\
\hline
\end{tabular}

performance in the context of digital finance innovation, where the firm's competencies and connotations are shown in Table 9. Empirical results show that (1) the servicerelated capabilities of green manufacturing firms can lead to collaboration, integration, and coordination across regions and departments and with customers or partners, which, in turn, drives performance improvement (Parida et al. 2015). However, this requires the use of innovation governance strategies (SjoDin et al., 2018) and digital capabilities (Martín-Pea et al., 2019), among others, as mediating variables to unlock the benefits of servitization in green manufacturing firms. (2) In the context of digital finance innovation, companies need to digitally upgrade their existing technological capabilities, employee skills, marketing capabilities, etc. For example, the results of Nasiri et al. (2020) showed that digital workforce and orchestration capabilities show a positive relationship with corporate financial performance. Hasselblatt et al. (2018), Büchi et al. (2020), and Szász et al. (2020) confirm that green manufacturing companies with a broader and more proficient range of Industry 4.0-related technologies such as IoT tend to have better operational performance and business performance and can more take full advantage of the opportunities presented by Industry 4.0. The IT capabilities, IT systems (Zhang and Hartley 2018), and ATM technologies of these companies enable them to increase their production capacity, push the boundaries of traditional production activities, and thus improve their performance (Szalavetz, 2018). In addition, firms that are more absorptive, more entrepreneurial, and more proactive tend to more fully transform technological advantages into corporate competitiveness (Rehman, 2020). (3) Dynamic capabilities are a strong focus for scholars of enterprise capabilities. Web capabilities, orchestration capabilities, and platform capabilities can all be considered as part of dynamic capabilities. Platform capabilities refer to the ability of firms to deploy internal and external resources based on the Internet, which helps them integrate and allocate resources, share knowledge, and respond to highly variable market demands. Network capability is the ability of an organization to create internal and external interdependencies to respond to external changes. Orchestration capabilities refer to the ability of firms to set goals, legitimize them, and build corresponding expertise at different stages of development. Due to the complexity of digital technology, dynamic capabilities are essential for companies to internalize their various resources into a competitive advantage in a highly volatile environment. In addition, during internalization, the institutional environment of the organization and the learning ability of individuals determine the extent of knowledge acquisition, which is relevant in terms of the firm's ability to develop its dynamics (Jiang et al. 2020). The dynamic capabilities of companies with a high level of digital transformation maturity often provide strategic guidance to companies in terms of process, technology, organization, and transformation (Lin et al. 2020). (4) Digital innovation capabilities, on the one hand, act as a mediating mechanism between the external environment and firm performance (Hanelt et al., 2020). On the other hand, it can also act as a direct antecedent to sales performance and customer relationship improvement (Kolbe et al. 2021). As a dependent variable for firms, digital innovation is often influenced by the capabilities mentioned earlier, such as the level of digital technology, digital analytical capabilities, and organizational variables (Saldanha et al. 2017). 
Table 9 Firm capabilities mentioned in the articles

\begin{tabular}{lll}
\hline & Firm capability & Concept \\
\hline 1 & Service innovation & $\begin{array}{c}\text { Service innovation strategies involve the ability to develop new } \\
\text { service offerings that create value for customers }\end{array}$ \\
2 & Servitization & The process of increasing value by adding services to products \\
3 & Digitalization & $\begin{array}{c}\text { Digitalization refers to the growing use of digital technology in green } \\
\text { manufacturing }\end{array}$ \\
4 & Intellectual capital & Intellectual capital is an intangible resource that can generate value \\
& & in the future, including human capital, relational capital, and struc- \\
& & tural capital \\
5 & Technology standardization capability & Technology standardization focuses on the formation of technology
\end{tabular}

$5 \quad$ Technology standardization capability

ogy standardization focuses on the formation of technology standards, motivation, the initial factors, the impact factors, the formation process of technology standards, and the competition and diffusion of standards at the industrial level

$6 \quad$ IT capability

It includes IT infrastructure flexibility, which has developed the technological base on which current and future IT applications are built, and IT technical skills, which constitute the know-how required to develop IT applications by using existing technology and to operate them either to provide a service or to make the products

7 Absorptive capacity

ACAP refers to the ability of a firm to acquire, assimilate, transform, and exploit knowledge-based resources

$8 \quad$ Digital platform capability

It represents the ability to deploy ICT-based resources in combination with other internal and external resources

$9 \quad$ Network capability

It refers to the coordination of groups and individuals that share a standard structure and an expected result, the internal communication of the external knowledge, the relational skills for handling diverse individuals, and the partners' knowledge

10 Networking capability

The ability to develop and deploy a network to accomplish specific goals focused on the acquisition of complementary external resources

11 Digital-related human capability

The boundless employee capabilities enable people to operate in the digital era with adaptable mindsets, skillsets, and digital know-how

Martín-Pea et al. (2019)

12 Digital-related collaboration capability

The bundle of firm capabilities created by digitality through collaborative activities with both external and internal partners

13 Digital-related technical capability

The bundle of firm capabilities that facilitate technological implementation and operation in the digital era

14 Digital-related innovation capability

The boundless firm capabilities generate new knowledge, new products and services, and new solutions through digitalization

15 Digital innovation capability

Digital innovation is defined as creating new market offerings or changes that result from the use of digital technologies

Nasiri et al. (2020)

Hanelt et al. (2021) 
Table 9 (continued)

\begin{tabular}{|c|c|c|c|}
\hline & Firm capability & Concept & Source \\
\hline \multirow[t]{2}{*}{16} & Dynamic capability & $\begin{array}{l}\text { Dynamic capability is an organization's capacity to purposefully } \\
\text { create, extend, or modify its resource base to achieve sustainable } \\
\text { advantages through adaptation to the changing shape of the external } \\
\text { environment }\end{array}$ & Zeng et al. (2017) \\
\hline & & $\begin{array}{l}\text { Dynamic capabilities comprise } 3 \text { broad clusters: sensing opportu- } \\
\text { nities (and threats), seizing opportunities, and transforming by } \\
\text { organizing resources and renewing organizations to their relevant } \\
\text { business model }\end{array}$ & Lin et al. (2020) \\
\hline 17 & Process capability & $\begin{array}{l}\text { The ability to optimize manufacturing processes with advanced tech- } \\
\text { nologies enables new value creation in operations, supply chain, } \\
\text { and product life cycle }\end{array}$ & \\
\hline 18 & Technology capability & $\begin{array}{l}\text { The ability to connect intelligent machines, storage systems, and } \\
\text { production facilities can facilitate information exchanges and data } \\
\text { analyses to predict failures and independent configurations }\end{array}$ & \\
\hline 19 & Organizational capability & $\begin{array}{l}\text { The capabilities to implement suitable strategies in a changing envi- } \\
\text { ronment, including intelligent manufacturing transformation and } \\
\text { developing organizational capabilities, must include top manage- } \\
\text { ment support and decision-making, talent, workforce training, and } \\
\text { education and knowledge }\end{array}$ & \\
\hline 20 & Transformation capability & $\begin{array}{l}\text { The capability to transform the abstract Industry } 4.0 \text { concept into a } \\
\text { practical application and evaluation of process systems }\end{array}$ & \\
\hline 21 & Digitally transforming capability & $\begin{array}{l}\text { The capability of executing a digital transformation strategy, includ- } \\
\text { ing digital-savvy skills, digital intensity, and context for action and } \\
\text { interaction }\end{array}$ & \\
\hline 22 & Innovation capability & $\begin{array}{l}\text { Innovation capability is the organization's ability to gather informa- } \\
\text { tion and create the knowledge needed to develop and implement } \\
\text { new products, processes, and services }\end{array}$ & Zhang and Hartley (2018) \\
\hline 23 & Global service innovation capability & $\begin{array}{l}\text { The development of global service innovation capabilities, grouped } \\
\text { across } 4 \text { dimensions: developing global customer insights, integrat- } \\
\text { ing global knowledge, creating global service offerings, and build- } \\
\text { ing global digitalization capabilities }\end{array}$ & Parida et al. (2015) \\
\hline 24 & Digitalization capability & $\begin{array}{l}\text { Digitalization capabilities include intelligence, connection, and } \\
\text { analytic capabilities }\end{array}$ & \\
\hline 25 & IoT capability & $\begin{array}{l}\text { IoT capabilities are identified as digital business model development, } \\
\text { scalable solution platform building, value selling, value delivery, } \\
\text { and business intelligence and measurement }\end{array}$ & Hasselblatt et al. (2018) \\
\hline 26 & Orchestration capability & $\begin{array}{l}\text { Orchestration capabilities are necessary to ensure co-evolution, } \\
\text { albeit with a different interpretation depending on the platform } \\
\text { development stage, including targeting capability, legitimizing and } \\
\text { envisioning capability, and expertise building capability }\end{array}$ & \\
\hline
\end{tabular}

\section{Cluster 3 (green): digital finance innovation, Industry 4.0, and supply chain management}

The keywords in cluster 3 consist mainly of the keywords corresponding to the green nodes. Table 10 shows specifically the keywords under this cluster, as well as the frequency of each keyword in conjunction with other keywords (total link strength), the frequency of the keywords themselves (occurrences), and the average number of references (avg. citations). According to Table 9, this cluster focuses on digital finance innovation, Industry 4.0 (artificial intelligence, process innovation, intelligent factory, intelligent green manufacturing), and supply chain management (supply chain management, circular economy, IoT). Meanwhile, according to Fig. 10, it can be seen that research about the Internet started earliest, showing sky blue. Immediately afterward, research on process innovation and supply chain management appeared, showing a green color. In recent years, the research hotspots have been topics related to intelligent green manufacturing, and these keywords appear yellow and orange on the map, which is in line with the overall transformation trend in green manufacturing. From the Internet era to the information age to the current digital intelligence era, the green manufacturing industry has constantly been using new technologies to achieve industrial upgrading and iteration. 
Table 10 The keywords of cluster 3

\begin{tabular}{lllll}
\hline Cluster & Label & $\begin{array}{l}\text { Total link } \\
\text { strength }\end{array}$ & Occurrences & Avg. citations \\
\hline 3, green & Artificial intelligence & 20 & 5 & 12 \\
& Automation & 37 & 10 & 32.5 \\
& Big data & 34 & 9 & 19.89 \\
& Circular economy & 26 & 5 & 38.8 \\
& Efficiency & 42 & 13 & 19.08 \\
& 4th industrial revolution & 27 & 10 & 13.6 \\
& Internet & 112 & 31 & 29.68 \\
& IOT & 50 & 12 & 8.75 \\
& New technology & 23 & 7 & 17.29 \\
& Process innovation & 30 & 8 & 31.25 \\
& Intelligent factory & 23 & 7 & 11 \\
& Intelligent manufacturing & 31 & 14 & 34.38 \\
\hline Supply chain management & 31 & 8 & \\
\hline
\end{tabular}

The literature in cluster 3 is structured around the context of Industry 4.0. (1) Industry 4.0 is the fourth industrial revolution led by intelligent green manufacturing, with ICT, IoT, and CPS as the technological basis for the intelligent transformation of green manufacturing, resulting in a vertically integrated and networked green manufacturing system. Intelligent factories and intelligent production are the two main themes of Industry 4.0. The former focuses on the realization of intelligent production systems and processes and networked distributed production facilities. The latter deals with the management of production logistics throughout the enterprise, human-machine interaction, and the application of 3D technology in industrial production processes. Along with the new era of digital, intelligent, and automated technologies, intelligent factories facilitate communication between factories and markets through automated mechanisms such as interconnection with users and other physical devices, thus making possible a new wave of green manufacturing innovation (Sjodin et al. 2018). Intelligent factories can have a range of benefits such as improved process efficiency, product quality, sustainability, safety, and cost reduction, resulting in a transformative technological and organizational impact on green manufacturing companies (Cagliano et al. 2019). Scholars have found that the depth and breadth of Industry 4.0 are closely related to the growth opportunities for companies (Büchi et al., 2020). However, most companies still lack insight into the challenges and resources for implementing intelligent factories in the transition from traditional to intelligent green manufacturing (Shi et al. 2020). Therefore, there is a need to reinvent a business model that can "self-adapt, responding to external stimuli and triggering digital finance innovation through its flexibility and adaptability". On the one hand, technological innovations can increase the opportunities to develop intelligent products and create an innovation ecosystem focused on intelligent products (Kahle et al. 2020), while on the other hand, innovations at the organizational level, such as soft corporate capabilities, are seen as equally important, such as continuous learning, flexibility, creativity, and analytical skills. (2) The era of Industry 4.0 has placed new demands on the supply chain management of green manufacturing enterprises. The first is to meet personalized demand, where companies need to connect with customers, suppliers, and logistics service providers to effectively link upstream and downstream services and organizations to respond quickly to consumer demand. The second is flexible production through intelligent networking for production that provides high-quality services. Then, there is modular and distributed production, decentralized through automation technology. Finally, there is standardization to gain synergies across the supply chain in the ecosystem. In the literature related to supply chain management, scholars have mainly studied the impact of Industry 4.0-related technologies (AM, 3D printing, AI, etc.) on the efficiency, processes, practices, and performance of supply chain management. Managing stakeholder relationships in the supply chain has always been a vital issue in the field, so the importance of synergies cannot be overstated. Intelligent applications, intelligent systems, etc., optimize supply chain business processes through digitization and automation of supply chain management (Hartley and Sawaya 2019), improve management efficiency (De 2021), reduce collaboration costs, and enhance supply chain performance in integration, operations, procurement, and distribution (Abdirad and Krishnan, 2020). In addition, digital green manufacturing technologies have brought about fundamental changes in the way companies produce and deliver their products, resulting in a shift in value logic towards a customer-centric focus along with a shift from a centralized to a decentralized supply chain, resulting in a more open business model (Bogers et al. 2016). Agile and 
lean supply chain management practices can significantly improve corporate performance (Raji et al. 2021). In the process, supply chain sustainability, green human resource management, and supply chain environmental cooperation tend to promote positive contribution of supply chain management practices to corporate market performance and financial performance (Agyabeng-Mensah et al., 2020), while information quality, information security, information systems, and information leakage may harm them (VafaeiZadeh et al., 2020). (3) Industry 4.0 is also closely related to the circular economy and offers new sustainable business models for the development of a circular economy for companies (Nascimento et al., 2018). Blockchain technologies and digital technologies (e.g., IoT, big data, data analytics) are seen as critical factors in driving the circular economy, and technologies related to Industry 4.0 effectively increase the efficiency of resource use and productivity (Kristoffersen et al. 2020). The emergence of intelligent green remanufacturing concepts also offers new opportunities for resource recycling and value recreation, which can effectively enrich the product range (Kerin and Pham 2020).

\section{Framework: digital finance innovation- intelligent servitization-capability}

\section{Theory logic}

Based on the abovementioned literature review, this paper proposes a path for realizing digital finance innovation in green manufacturing enterprises. In the digital economy, innovation in green manufacturing can no longer be advanced in the traditional sense of a linear process approach, but by companies using digital infrastructure, relying on platforms, lending to innovation ecosystems, forming unique value paths by integrating data resources, and creating value with heterogeneous players. This innovation model, known as "digital finance-innovation," has reshaped the logic of value creation in companies. Nambisan et al. (2017) argue that the essence of digital finance innovation is the dynamic process of "problem-solution" matching, including the matching of digital technologies, capabilities, and products. How companies use the digital infrastructure and coordinate heterogeneous players within the platform to participate in the process together is fundamental to the successful implementation of digital finance innovation. In the era of digital intelligence, the findings offer a research idea of "intelligent servitization - orchestration capability - digital finance innovation."

The application of digital intelligence in service innovation is a long-term trend. Both Germany's Industry 4.0 strategy and the Made in China 2025 strategy have made intelligent servitization an important goal in developing advanced green manufacturing, significantly accelerated by the global epidemic that broke out in early 2020 . Intelligent servitization reflects the importance of digital intelligence technology and encompasses a vital strategy of enterprise intelligence and servitization, manifested in a high degree of integration between digital technology innovation and enterprise management innovation. In addition, orchestration functions are becoming increasingly important for companies undergoing intelligent green manufacturing and service transformation, and orchestration is a key to facilitating the collaborative evolution of network participants and capturing value.

Regarding the antecedents of digital finance innovation, there are several drivers, with Abrell et al. (2016) suggesting in a B2B context that how firms manage various types of customer knowledge and user knowledge is an essential antecedent of digital technology innovation. Divide digital finance innovation generation into four stages: initiation, development, application, and exploitation. The start-up phase involves developing a digital strategy, organizing digital resources, and improving digital capabilities. The development phase requires open innovation, situational interaction, and continuous iteration, and in the application and development phase, the value network needs to be redefined and organized for change. In addition, the most direct mechanisms driving digital innovation are distributed, combinatorial innovation, and multi-subject platforms with digital capabilities that are a key to digital innovation. The former implies that digital finance innovations often result from collecting and recombining digitally coded information across organizational boundaries. At the same time, the latter refers to the fact that new digital solutions often integrate existing modules through embedded digital capabilities or fuse different modules with the same criteria (Ciriello et al. 2018). As digital innovation becomes more embedded within organizations, summarize the sufficient factors for digital innovation: organizational capacity, organizational structure, organizational culture, and digital technology mix. Nasiri et al. (2020) empirically investigated the positive relationship between firm capabilities and digital innovation. It can be seen that the drivers of digital finance innovation can be summarized as technological, capability, and strategic factors.

\section{Intelligent servitization and digital finance innovation}

Intelligent servitization is the provision of technologyenabled services that rely on digital components embedded in physical products (Bustinza et al. 2015), enabling value creation and capture through monitoring, control, 
optimization, and autonomous functions. Therefore, the concept of intelligent servitization reflects the importance of intelligent technology as well as encompassing essential strategies for the intelligence and servitization of companies, which overlap with the drivers of digital finance innovation mentioned above. In addition, intelligent servitization focuses on improving the efficiency of products and services through digital technology (components) on the one hand. It can develop a competitive advantage and enhance the effectiveness of companies through digital technology on the other hand. Research on intelligent servitization and digital finance innovation is divided into studies on impact effects and impact mechanisms. Some studies illustrate the critical role of intelligent services for product innovation based on theoretical analysis or case studies at the level of innovation performance. For example, Symrise uses intelligent solutions to improve product development efficiency and novelty through ample data storage and analysis. Using methods such as regression analysis, some studies have explored the relationship between intelligence services and firms' innovation performance and found that digital services can enhance both financial and non-financial (innovation performance) performance of firms. It has also been argued that the relationship between servitization and business performance is not simply linear but shows an inverted U-shaped functional performance. Scholars argue that intelligent services can improve enterprise output and productivity by optimizing traditional factors and nurturing high-end factors at the level of innovation mechanisms. That orchestration mechanism based on the perceptiveness, connectivity, personalization, and dynamism of intelligent services influences management and performance innovation. It can be seen that there is a positive correlation between intelligent servitization and digital finance innovation, but the form and extent of the impact vary in different contexts.

\section{Orchestration capabilities and digital finance innovation}

In the era of digital intelligence, the green manufacturing industry is gradually forming an ecosystem by building a digital platform by revolutionizing the traditional way of resource interaction and value distribution. The value network between multiple actors such as suppliers, companies, and consumers is becoming increasingly complex. In this value network, orchestration capabilities are gradually becoming an essential factor in the ability of companies to transform internal and external resources into a competitive advantage and promote the orchestration evolution of the participants in the organizational network (Forkmann et al. 2018). Research on orchestration capabilities is not yet long in coming, primarily exploratory case studies and lacking in quantitative research. There is less research on empirical relationships and measurement, and propositions are mostly made but not yet tested. Dhanaraj and Parkhe (2006) argue that the higher the level of hub firm synergy, the greater the output of network innovation. Excellence in orchestration capabilities facilitates the ability of firms to successfully innovate and capture sufficient value to achieve superior long-term financial performance (Teece 2007). In future-oriented value creation, orchestration capabilities are needed to seek incremental and breakthrough innovations and new business opportunities (Ritala et al., 2009). In the paper, Helfat and Raubitschek (2018) suggests that innovation and sensing/scanning capabilities in orchestration capabilities facilitate platform leaders to exploit opportunities and respond to threats and that integration capabilities facilitate the design and transformation of business models, reduce transaction costs, narrow the boundaries of platform leaders, expand the boundaries of ecosystems, capture more value, and enhance positive cross-edge network effects and thus create value. Mitera found that network capabilities positively affect firm performance, that product innovation plays a partially mediating role, and that relationship propensity plays a positive moderating role in the effect of network capabilities on product innovation. It is thus clear that there is an important positive influence of orchestration capability in the innovation process of firms, but the mechanism of influence varies, with some scholars using it as a direct driver and others using it as a mediating or moderating factor; therefore, this study includes orchestration capability as a critical variable in the research model.

\section{Theory model construction}

In order to construct a theory of digital finance innovation realization paths in green manufacturing enterprises, this paper identifies critical conceptualizations and the relationships between them and then further divides them into different dimensions based on the existing literature and operationalizes them through a model.

First of all, academics mainly classify digital finance innovation as product innovation, service innovation, process innovation, and business model innovation. Digital innovation changes the nature and structure of an enterprise's original products and services and changes the way value is created and the path of value distribution. The essential logic follows the theoretical paradigm of S-O-R; i.e., in the context of intelligent service delivery, digital technology becomes the driver of change for companies, which internalize digital technology into corporate capabilities and then take a series of transformative measures that bring new ways of creating value and realizing value for the company. As digital technology and firm capabilities work together to ultimately bring about an increase in the amount of firm value, this study provides a new classification of digital finance innovation types from value creation. 
Firstly, value creation can usually be decomposed into two levels: the increase in value and the emergence of new elements, adding new products and services (Lepak and Smith 2007). The digital economy has several characteristics of value creation, such as efficiency, convergence, and rebirth (Teece 2018).

This paper, therefore, classifies digital innovation into three types: efficient, generative, and convergent. Efficient digital innovation performance means that firms use digital technologies and corporate capabilities to improve the efficiency of business activities to create value, where no new elements emerge in the process of increasing the volume of value, where the optimizing effect of digital technologies is marginal and diminishing, and where the innovation performance brought about is continuous and progressive. However, no new products or business models emerge. Generative digital innovation performance means that companies use digital technologies and corporate capabilities to generate new value-creating elements for the enterprise. In this phase, the orchestration capabilities and value co-creation between multiple entities allow users to increase the crossborder integration between co-creation and sharing, expanding the path to enterprise value creation and value realization. Convergent digital innovation performance refers to digital technologies and enterprise capabilities to reshape a company's competitive advantage through the convergence and generation of iterative corporate business models. The availability of digital technologies and the interconnected components of intelligent services bring convergence and generation to business innovation when disruptive value creation mechanisms will lead to business model disruption and innovation (Skog et al. 2018) and can drive overall industry transformation and upgrading.

Secondly, this study refers to Frank et al.'s (2019) classification of enterprise service types and digitization levels, combined with the different stages of servitization as summarized by Jiamian Tian et al., and ultimately, the level of intelligent servitization of green manufacturing enterprises is classified into three stages, namely non-digital servitization, digital servitization, and intelligent servitization. In the transition phase from non-digital to digital services, companies focus on a cost leadership strategy. The absorption of new knowledge comes mainly from internal staff, independent research and development, and the extraction of experience from daily operations and management. Service improvement at this time still relies, on the one hand, on the management and labor skills of the firm. On the other hand, it is beginning to shift towards reliance on digital technology. Digital platforms are beginning to play an essential role in shifting from digital to intelligent servitization. Green manufacturing companies use the front-end online trading platform and the back-end digital production platform to carry out value coordination activities and leverage the platform to drive digital innovation. As companies move into the intelligent services phase, they will further integrate resources in the ecosystem to provide future-proof intelligent services.

Finally, in the context of the platform, the literature has broadly categorized the synergy capabilities of companies into strategic targeting capability, legitimizing and envisioning capability, and expertise building capability. This study adopts Jiamian Tian's definition of the dimensions; i.e., target capability is the ability of a firm to deploy resources and formulate development plans in various areas (production management, product development, and design, marketing, etc.). Innovation in the positioning of green manufacturing companies helps internal employees and external stakeholders to better identify the organization's identity. Legitimizing and envisioning capability is when companies commit and assign the proposed value vision and vision through a legitimizing contract to guarantee the distribution of value that attracts participants from within and outside the network. Expertise building capability offers the possibility for companies to realize the value vision presented in the previous phase. By acquiring and assimilating new knowledge and digesting and using it to provide professional services (solution services, technical advice, etc.), companies can stimulate the innovative power of the members of their networks.

With the increase in the level of intelligent servitization of companies and the high level of orchestration capabilities, the type of innovation in companies has evolved from traditional non-digital innovation to digital innovation. In enabling digital innovation in companies, digitization and servitization enable companies to improve process efficiency due to their transition to digital services. At the same time, advanced orchestration capabilities allow companies to focus on fostering partner trust, managing value conflicts, and legitimizing strategic objectives, thus guaranteeing efficient digital innovation. Along with transforming enterprises into intelligent services, the intelligent upgrade of digital technology brings about digital service innovation in enterprises. Collaborative capabilities step into a high stage and the knowledge embedding and structural embedding of other multiple subjects, such as consumers, enhance the ability of enterprises to develop products and thus improve digital product innovation performance, both of which are generative digital innovations. Finally, when the company's intelligent service and orchestration capabilities reach high levels simultaneously, the company will achieve business model innovation, form a unique competitive advantage, and obtain integrated digital innovation. In summary, this paper proposes a digital innovation realization path in the framework of intelligent servitization-collaborative capabilities (Fig. 11). 


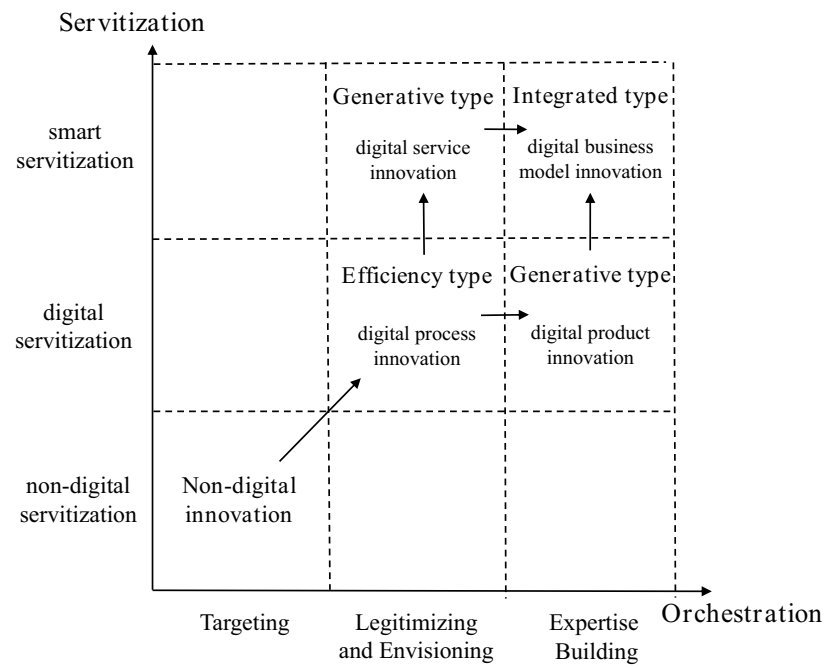

Fig. 11 The path of digital innovation in manufacturers

\section{Conclusion}

\section{General findings}

This paper identifies research hotspots, research lines, and research clusters under this topic through a literature analysis of digital innovation in green manufacturing enterprises. Using bibliometrics, we identified the most influential journals on this topic, namely Journal of Manufacturing Technology Management, Technological Forecasting and Social Change, Industrial Marketing Management, and Journal of Business Research. The most influential research teams are those of Parida V, Sjodin DR, and others, and the most influential literature, among other things. In terms of the research lineage, 2015 is taken as a rough time divider, with the research before this laying the theoretical foundation for the servitization of green manufacturing enterprises. The research after this focuses on theoretical construction and practical exploration in the context of Industry 4.0. In terms of research clustering, it can be divided into three main categories, namely (i) digital innovation, servitization, and business models; (ii) digital innovation, enterprise capabilities, and performance; and (iii) digital innovation, Industry 4.0, and supply chain management. This paper classifies the types of digital innovation from the perspective of value creation and distills the realization paths of digital innovation in green manufacturing enterprises under the perspective of intelligent servitization and collaborative capabilities. This paper classifies the types of digital innovation from the perspective of value creation and distills the realization paths of digital finance innovation in green manufacturing enterprises under the perspective of intelligent servitization and collaborative capabilities.

\section{Limitations and future research}

This paper has limitations in the following areas. Firstly, as the core idea of the bibliometric approach is to determine the importance and influence of a document by the number of citations it receives, the algorithm itself has certain limitations. This will make it possible for us to fail to identify some of the most recently published and valuable literature. This paper is aware of this problem and has tried to avoid this error in literature identification and analysis by manual screening and close reading, but there may still be some omissions. Secondly, the subject of this paper is green manufacturing companies, resulting in the applicability of our findings in other industries still to be verified. Thirdly, digital finance innovation is still a young topic, and scholars are still in the proliferation phase of their research, so the findings of this paper may need constant adjustment and refinement in the future. Fourthly, the digital finance innovation realization path proposed in this paper is obtained by extrapolation based on literature analysis, and the theoretical framework needs to be further verified in the future through case studies or empirical methods to verify its validity.

In order to fill the gaps in existing research and better understand digital finance innovation in green manufacturing companies, this paper proposes the following future research directions. Firstly, there is an urgent need for further development of conceptual measures related to digital finance innovation. The theoretical foundations of digital finance innovation have been developed mainly by academics, but the related scales are not mature and need to be improved. The lack of scales will prevent scholars from testing and refining theories through empirical methods. Secondly, it focuses on the driving and influencing mechanisms of digital finance innovation in green manufacturing enterprises. Based on the service theory and dynamic capability theory, this paper initially proposes the realization path of digital finance innovation. However, on the one hand, the complex internal mechanisms still need to be further explored and refined by case studies, and on the other hand, the driving and influencing mechanisms of digital finance innovation still need more exploration and analysis. Thirdly, digital finance innovation is an interdisciplinary topic that requires us to integrate knowledge from multiple disciplines, such as computing, management, and economics, to conduct research. Therefore, in the future, we should try to use crossborder theories and methods to provide better explanations for the digital finance innovation activities of companies. Fourthly, there is still a need for more advanced research in digital finance innovation in green manufacturing. As digital finance innovation is an emerging concept, no universal success stories have yet emerged in practice. Therefore, we need to conduct case studies of representative enterprises to show the similarities and differences between different enterprises 
to refine influential theories better and guide the practice of enterprises through the a priori nature of theories.

Author contribution Lei Shen: conceptualization, data curation, methodology, and writing of original draft. Xi Zhang: Data curation, review, and editing. Hongda Liu: writing and editing.

Funding This research was funded by the Graduate Student Innovation Fund of Donghua University (GSIF-DH-M-2021005).

Data availability The data that support the findings of this study are openly available on request.

\section{Declarations}

Ethics approval and consent to participate The authors declare that they have no human participants, human data, or human tissues.

Consent for Publication The authors do not have any individual person's data in any form.

Competing interests The authors declare no competing interests.

\section{References}

Van Raan T (1996) Advanced bibliometric methods as quantitative core of peer review based evaluation and foresight exercises. Scientometrics 36(1):397-420

Abdirad M, Krishnan K (2020) Industry 4.0 in logistics and supply chain management: a systematic literature review. Eng Manag J $1: 1-15$

Abrell T, Pihlajamaa M, vom Brocke J, Kanto L (2016) The role of users and customers in digital innovations form B2B manufacturing firms. Inf Manag 53(3):324-335

Agyabeng-Mensah Y, Ahenkorah E, Afum E (2020) Examining the influence of internal green supply chain practices, green human resource management and supply chain environmental cooperation on firm performance. Supply Chain Manag 25(5):585-599

Ahmad M, Zhao ZY, Rehman A, Shahzad M, Li H (2019) Revealing long- and short-run empirical interactions among foreign direct investment, renewable power generation, and $\mathrm{CO} 2$ emissions in China. Environ Sci Pollut Res 11(6):1154-1182

Ahmad M, Jabeen G, Irfan M, Ik C, Rehman A (2021) Do inward foreign direct investment and economic development improve local environmental quality: aggregation bias puzzle. Environ Sci Pollut Res 25(12):18-40

Allmendinger G, Lombreglia R (2005) Four strategies for the age of smart services. Harv Bus Rev 83(10):131-134

Barua A, Konana P, Whinston A (2004) An empirical investigation of net-enabled business value. MIS Q 28(4):585-620

Beverungen D, Kundisch D, Wünderlich N (2020) Transforming into a platform provider: strategic options for industrial smart service providers. J Serv Manag 32(4):507-532

Beverungen D, Müller O, Matzner M (2017) Conceptualizing smart service systems. Electron Mark 29(1):7-18

Bogers M, Hadar R, Bilberg A (2016) Additive manufacturing for consumer-centric business models: implications for supply chains in consumer goods manufacturing. Technol Forecast Soc Chang 102(10):225-239
Burstrm T, Parida V, Lahti T (2021) AI-enabled business-model innovation and transformation in industrial ecosystems: a framework, model and outline for further research. J Bus Res 127(1):85-95

Bustinza O, Parry G, Herrero F (2015) Link channels or how to enhance upstream-downstream relations in servitized contexts. Dyna (Bilbao) 90(6):588-589

Cenamor J, Sjödin D, Parida V (2017) Adopting a platform approach in servitization: leveraging the value of digitalization. Int J Prod Econ 192 No.SI:54-65

Vishal D et al (2021) Impact of renewable energy consumption, financial development and natural resources on environmental degradation in OECD countries with dynamic panel data. Environ Sci Pollut Res Int 12(7):05-22

Dhanaraj C, Parkhe A (2006) Orchestrating innovation networks. Acad Manag Rev 31(3):659-669

Ds A, Vpa B, Mk B (2019) Relational governance strategies for advanced service provision: multiple paths to superior financial performance in servitization. J Bus Res 101:906-915

Eck N, Waltman L (2010) Software survey: VOSviewer, a computer program for bibliometric mapping. Scientometrics 84(2):523-538

Edu SA, Agoyi M, Agozie DQ (2020) Integrating digital innovation capabilities towards value creation: a conceptual view. Int J Intell Inf Technol 16(4):37-50

Forkmann S, Henneberg SC, Mitrega M (2018) Capabilities in business relationships and networks: research recommendations and directions. Ind Mark Manag 74:4-26

Frank AG, Mendes G, Ayala NF et al (2019) Servitization and Industry 4.0 convergence in the digital transformation of product firms: a business model innovation perspective. Technol Forecast Soc Chang 141:341-351

Büchi G, Cugno M, Castagnoli R (2020) Smart factory performance and Industry 4.0. Technol Forecast Soc Chang 150(119790)

Garfield E (2009) From the science of science to Scientometrics visualizing the history of science with HistCite software. J Informet 3(3): 173-179

Gebauer H, Arzt A, Kohtamki M et al (2020) How to convert digital offerings into revenue enhancement - conceptualizing business model dynamics through explorative case studies. Ind Mark Manag 91:429-441

Giovanni PD (2020) Smart Supply Chains with vendor managed inventory, coordination, and environmental performance. Eur J Oper Res 292(2):515-531

Magaly GM, Merigó JM, Hugo BF (2018) Knowledge management: a global examination based on bibliometric analysis. Technol Forecast Soc Chang 140:194-220

Goduscheit RC, Faullant R (2018) Paths towards radical service innovation in manufacturing companies - a service-dominant logic perspective. J Prod Innov Manag 35(5):701-719

Grieger M, Ludwig A (2019) On the move towards customer-centric business models in the automotive industry - a conceptual reference framework of shared automotive service systems. Electron Mark 29(3):473-500

Jiang H, Sun S, Xu H et al (2020) Enterprises' network structure and their technology standardization capability in Industry 4.0. Syst Res Behav Sci 37(4):749-765

Hanelt A, Firk S, Hildebrandt B et al (2020) Digital M\&A, digital innovation, and firm performance: an empirical investigation. Eur J Inf Syst 30(1):3-26

Hartley JL, Sawaya WJ (2019) Tortoise, not the hare: digital transformation of supply chain business processes. Business Horizons 62(6):707-715

Helfat CE, Raubitschek RS (2018) Dynamic and integrative capabilities for profiting from innovation in digital platform-based ecosystems. Res Policy 47(8):1391-1399 
Henfridsson O, Nandhakumar J, Scarbrough H et al (2018) Recombination in the open-ended value landscape of digital innovation. Inf Organ 28(2):89-100

Hsi-Peng, Weng, Chien-I (2018) Smart manufacturing technology, market maturity analysis and technology roadmap in the computer and electronic product manufacturing industry. Technol Forecast Soc Chang, Vol. 133, pp. 85-94.

Merigó JM, Mas-Tur A, Roig-Tierno N et al (2015) A bibliometric overview of the Journal of Business Research between 1973 and 2014. J Bus Res 68(12):2645-2653

Müller JM, Buliga O, Voigt KI (2018) Fortune favors the prepared: how SMEs approach business model innovations in Industry 4.0. Technol Forecast Soc Chang 132:2-17

Müller JM (2019) Business model innovation in small-and mediumsized enterprises: strategies for Industry 4.0 providers and users. J Manuf Technol Manag 30(8):1127-1142

Kahle JH, Marcon R, Ghezzi A et al (2020) Smart products value creation in SMEs innovation ecosystems. Technol Forecast Soc Chang 156(120024)

Kerin M, Pham DT (2020) Smart remanufacturing: a review and research framework. J Manuf Technol Manag 31(6):1205-1235

Kamran KM et al (2021) Role of financial development, environmental-related technologies, research and development, energy intensity, natural resource depletion, and temperature in sustainable environment in Canada. Environ Sci Pollut Res Int 52(8):72-99

Khin S, Ho TC (2018) Digital technology, digital capability and organizational performance: a mediating role of digital innovation. Int J Innov Sci 11(6):177-195

Kiel D, Arnold C, Voigt KI (2017) The influence of the industrial internet of things on business models of established manufacturing companies - a business level perspective. Technovation 68:4-19

Kohli R, Melville NP (2019) Digital innovation: a review and synthesis. Inf Syst J 29(1):200-223

Kolbe D, Calderón H, Frasquet M (2021) Multichannel integration through innovation capability in manufacturing SMEs and its impact on performance. J Bus Ind Mark 84(2):523-538

Kristoffersen E, Blomsma F, Mikalef P et al (2020) The smart circular economy: a digital-enabled circular strategies framework for manufacturing companies. J Bus Res 29(1):200-223

Kumar B, Sharma A, Vatavwala S et al (2020) Digital mediation in business-to-business marketing: a bibliometric analysis. Ind Mark Manag 85:126-140

Lafont J, Ruiz F, Gil-Gómez H et al (2020) Value creation in listed companies: a bibliometric approach. J Bus Res 84(2):523-538

Lepak DP, Smith KG (2007) Value creation and value capture: a multilevel perspective. Acad Manag Rev 115:5428-5434

Lerch C, Gotsch M (2015) Digitalized product-service systems in manufacturing firms: a case study analysis. Res Technol Manag 58(5):45-52

Szász L, Demeter K, Rácz B-G et al (2020) Industry 4.0: a review and analysis of contingency and performance effects. J Manuf Technol Manag 32(3):667-694

Lin TC, Sheng ML, Jeng WK (2020) Dynamic capabilities for smart manufacturing transformation by manufacturing enterprise. Asian J Technol Innov 28(3):403-426

Lindhult E, Chirumalla K, Oghazi P et al (2018) Value logics for service innovation: practice-driven implications for service-dominant logic. Serv Bus 12(3):457-481

Liu H, Yao P, Wang X, Huang J, Liying Y (2021) Research on the peer behavior of local government green governance based on SECI expansion model. Land 10:472

Llanos-Herrera GR, Merigo JM (2018) Overview of brand personality research with bibliometric indicators. Kybernetes 48(3):546-569
Kohtamäki M, Parida V, Oghazi P et al (2019) Digital servitization business models in ecosystems: a theory of the firm. J Bus Res 104:380-392

Hasselblatt M, Huikkola T, Marko KM, Nickell D (2018) Modeling manufacturer's capabilities for the internet of things. J Bus Ind Mark 33(6):822-836

Giudice MD, Scuotto V, Papa A et al (2020) A self-tuning model for smart manufacturing SMEs: effects on digital innovation. J Prod Innov Manag 38(1):568-589

Mitrega $\mathrm{M}$ et al (2012) Networking capability in business relationships-concept and scale development. Ind Mark Manag 41(5):739-751

Martín-Pea ML, Sánchez-López JM, Diaz-Garrido E (2019) Servitization and digitalization in manufacturing: the influence on firm performance. J Bus Ind Mark 35(3):564-574

Naik P, Schroeder A, Kapoor KK et al (2020) Behind the scenes of digital servitization: actualising IoT-enabled affordances. Ind Mark Manag 89:232-244

Nambisan S (2018) Architecture vs. ecosystem perspectives: reflections on digital innovation. Inf Organ 28(2):104-106

Nambisan S, Lyytinen K et al (2017) Digital innovation management: reinventing innovation management research in a digital world. MIS Q 41(1):223-238

Nascimento D, Alencastro V, Quelhas OLG et al (2018) Exploring Industry 4.0 technologies to enable circular economy practices in a manufacturing context - a business model proposal. J Manuf Technol Manag 30(3):607-627

Nasiri M, Saunila M, Ukko J et al (2020) Shaping digital innovation via digital-related capabilities. Inf Syst Front:1-18

Nasreen S, Anwar S, Ozturk I (2017) Financial stability, energy consumption and environmental quality: evidence from South Asian economies. Renew Sust Energ Rev 67(1):1105-1122

Parida V, Sjoedin DR, Lenka S et al (2015) Developing global service innovation capabilities: how global manufacturers address the challenges of market heterogeneity. Res Technol Manag 58(5):35-44

Cagliano R, Canterino F, Longoni A et al (2019) The interplay between smart manufacturing technologies and work organization: the role of technological complexity. Int J Oper Prod Manag 39(6/7/8):913-934

Ciriello RF, Richter A, Schwabe G (2018) Digital innovation. Bus Inf Syst Eng 60(6):563-569

Rajala R, Brax SA, Virtanen A et al (2018) The next phase in servitization: transforming integrated solutions into modular solutions. Int J Oper Prod Manag 39(5):630-657

Raji IO, Shevtshenko E, Rossi T et al (2021) Industry 4.0 technologies as enablers of lean and agile supply chain strategies: an exploratory investigation. The. Int J Logist Manag ahead-of-print (ahead-of-print)

Rehman A, Ma H, Ahmad M, Ozturk I, Ik C (2021) Estimating the connection of information technology, foreign direct investment, trade, renewable energy and economic progress in Pakistan: evidence from ARDL approach and cointegrating regression analysis. Environ Sci Pollut Res 72(3):1-13

Rehman N (2020) Information technology and firm performance: mediation role of absorptive capacity and corporate entrepreneurship in manufacturing SMEs. Tech Anal Strat Manag 32(9):1049-1065

Ritala P, Armila L, Blomqvist K (2009) Innovation orchestration capability-defining the organizational and individual level determinants. Int J Innov Manag 13(4):569-591

Saldanha T, Mithas S, Krishnan MS (2017) Leveraging customer involvement for fueling innovation: the role of relational and analytical information processing capabilities. MIS Q 41(1):267

Shi Z, Xie Y, Xue W et al (2020) Smart factory in Industry 4.0. Syst Res Behav Sci 37(4):607-617 
SjoDin DR, Vinit P, Markus L et al (2018) Smart factory implementation and process innovation: a preliminary maturity model for leveraging digitalization in manufacturing: moving to smart factories presents specific challenges that can be addressed through a structured approach focused on people. Res Technol Manag 61(5):22-31

Sklyar A, Kowalkowski C, Tronvoll B et al (2019) Organizing for digital servitization: a service ecosystem perspective. J Bus Res 104:450-460

Skog DA, Wimelius H, Sandberg J (2018) Digital disruption. Bus Inf Syst Eng 60(5):431-437

Szalavetz A (2018) Industry 4.0 and capability development in manufacturing subsidiaries. Technol Forecast Soc Chang 145:384-395

Teece DJ (2018) Profiting from innovation in the digital economy: enabling technologies, standards, and licensing models in the wireless world. Res Policy 47(8):1367-1387

Teece DJ (2007) Explicating dynamic capabilities: the nature and microfoundations of (sustainable) enterprise performance. Strateg Manag J 28(3):1319-1350

Vafaei-Zadeh A, Ramayah T, Hanifah H et al (2020) Supply chain information integration and its impact on the operational performance of manufacturing firms in Malaysia. Inf Manag 57(8): 103386

Wareham JD, Fox PB, Giner JLC (2013) Technology ecosystem governance. Organ Sci 25(4):1195-1215

Coreynen W, Matthyssens P, Van Bockhaven W (2016) Boosting servitization through digitization: pathways and dynamic resource configurations for manufacturers. Ind Mark Manag 60:42-53

Wise R, Baumgartner P (1999) Go downstream: the new profit imperative in manufacturing. Harv Bus Rev 28(1):89-96

Yoo Y, Henfridsson O, Lyytinen K (2010) Research commentary - the new organizing logic of digital innovation: an agenda for information systems research. Inf Syst Res 21(4):724-735

Zhang M, Hartley JL (2018) Guanxi, IT systems, and innovation capability: the moderating role of proactiveness. J Bus Res 90:75-86

Publisher's note Springer Nature remains neutral with regard to jurisdictional claims in published maps and institutional affiliations. 